\title{
Comprehensive Review of Keloid Formation
}

\author{
Abeer Shaheen ${ }^{1,2^{*}}$ \\ ${ }^{1}$ Master Degree of Dermatology, Tishreen University, Lattakia, Syria \\ ${ }^{2}$ Doctor at department of dermatology, Tishreen Hospital, lattakia. Syria
}

Received: September 19, 2017; Accepted: October 02, 2017; Published: October 12, 2017

*Corresponding author: Abeer Shaheen, MD, department of dermatology, Tishreen Hospital, Jableh, lattakia, Syria, Tel: 963994044175; E-mail: dr.abeer.a.shaheen@gmail.com

\begin{abstract}
Keloid is a benign fibrous growth, which presents in scar tissue of predisposed individuals. Although the pathogenesis of keloid disease is not well understood, it is considered to be the end product of an abnormal healing process. There are several molecules and cells implicated in keloid mechanism in relation to the normal wound healing process. However, it is possible that several factors such as age of onset, sex, cause of scarring, blood groups, anatomical site, presence of family history, number of injured sites (multiple/ single), and modifiable factors like delayed healing, and hypertension have an important role in keloid formation and consequentially in predicting keloid's behavior in response to treatment and prognosis. Keloids appear as firm, mildly tender, bosselated tumors with a shiny surface. The main differential diagnosis of keloid is hypertrophic scar, also called pseudokeloid, which not only a clinical challenges, but also histological challenge. No single therapeutic modality is best for all keloids. The location, size, and depth of the lesion; the age of the patient; and the past response to treatment determine the type of therapy used, so there are several options in keloid treatment. Prevention is the first rule in keloid therapy, so we must take special care in treating patients with a history of keloids. This review gives a comprehensive view of keloid formation (pathogenesis, risk factors, diagnosis, different diagnosis, histopathology, treatment and prevention) and this is the object of this review.
\end{abstract}

Keywords: Keloids; Pathogenesis; Risk factors; Diagnosis; Different diagnosis; Histopathology; Treatment; Prevention;

\section{Abbreviations}

ECM: Extracellular matrix

PDGF: Platelet-derived growth factor

TGF: Transforming growth factor

VEGF: Vascular endothelial growth factor

CTGF: Connective tissue growth factor

IFN-g: Interferon-g

IGF-IR: Insulin-like growth factor-1 receptor

\section{Definition}

Keloid is a benign fibrous growth, presents in scar tissue of predisposed individuals, extends beyond the borders of the original wound, doesn't usually regress spontaneously, and tends to recur after excision [1,2]. It is a result of irregular wound healing following skin insults (trauma, inflammation, surgery, burns...etc.), but sometimes occur spontaneously. Most keloids develop within 3 months of the injury, but some may occur up to 1 year after skin insults $[3,4]$. keloids are often pruritic and painful, in addition to significant effects of patient's quality of life, both physically and psychologically, especially in excessive scarring [5,6]. First described in the Edward Smith papyrus in Egypt around 1700 BC [7].

\section{Pathogenesis}

Although the pathogenesis of keloid disease is not well understood, it is considered to be the end product of an abnormal healing process. There are several molecules and cells implicated in keloid mechanism in relation to the normal wound healing process. Healing processes are classically divided into three phases: Hemostasis and Inflammatory phase, Proliferative phase; and Maturation and remodeling phase, although they also overlap each other. Some authors have suggested that keloid formation maybe related to an abnormal response to inflammation, while others suggested prolonged proliferative phase [6].

\section{Hemostatic and inflammatory phase}

The goal of this phase is to remove injured tissue and foreign bodies from the wound and restore immunological control. This phase begins immediately after the occurrence of trauma, and continues for 4-6 days.

Hemostasis is the process that responds to injury to stop blood loss by vascular and cellular responses. Immediately the injured vessels undergo vasoconstriction (10-15 $\mathrm{min}$ ) is followed by vasodilation due to activation of mast cells, which is important for the chemotaxis of neutrophils, macrophages, and lymphocytes. The increased blood flow, triggering the signs of inflammation, such as heat, edema and redness. Platelets aggregate at the site of injury, leading to blood clot (the coagulation system). Blood 
clot is temporarily seal the bleeding, and acts as a reservoir for growth factors and cytokines, and cell migration. Blood clots predominantly consist of fibrin, but other Extracellular Matrix (ECM) proteins, such as fibronectin, vitronectin, and thrombospondin, are also present. Possible involvements of fibrin and fibronectin in keloid pathogenesis have been suggested $[6,8]$.

After injury, resident mast cells degranulate and release histamine, bradykinins, and leukotrienes, which lead to the recruitment of immune cells. The first inflammatory cells arriving to the injury site are Neutrophils, which kill microbes, and provide a source of proinflammatory cytokines. Monocytes enter the wound bed and develop into activated macrophages, which secrete numerous growth factors and cytokines that act on fibroblast, endothelial cells, and keratinocytes, such as: PlateletDerived Growth Factor (PDGF), transforming growth factor TGF-a, TGF-b, and vascular endothelial growth factor VEGF. In addition to their involvements in the inflammatory phase, some of these growth factors and cytokines are also involved in the proliferative phase and have also been implicated to be abnormal in keloids [6,8].

\section{Proliferative phase}

It begins around the third day after injury, lasts for 2 to 3 weeks. The aim of this phase is to restore the function of injured tissue, through reepithelialization, neovascularization, fibroplasia. The sources of cytokines and growth factors involved in the proliferative phase are from both the inflammatory cells and the local cell population, including endothelial cells, keratinocytes, fibroblasts, and T cells [6,8].

Reepithelialization is the first visible event of the proliferative phase, which is characterized by the migration and proliferation of keratinocytes from the epidermis at the wound edge that occurs 1-2 days post-wounding. Although keloids are defined as a dermal disease involving fibroblasts, there is suggestion for keratinocyte involvements $[6,8]$.

Neovascularization is the process of new blood vessel formation (granulation tissue) in response to tissue malnutrition. New vessels are formed from solid endothelial sprouts that migrate from the wound edges to the central area. Chemical mediators like bradykinin and prostaglandin, from macrophages induce migration and mitosis of endothelial cells. Neoangiogenesis increases the recruitment of cells, such as macrophages and fibroblasts, to the wound site. Active neovascularization has been implicated in keloid disease. Vascular endothelial growth factors VEGF plays a significant role in neovascularization and have been linked to keloids disease. Platelet Derived Growth Factor (PDGF) and Connective Tissue Growth Factor (CTGF) are other growth factors that play an important role in the proliferative phase. These factors have been implicated in keloid formation $[6,8]$.

Fibroplasia; after injury, fibroblasts in normal tissue are attracted to the inflammation site, where they divide and produce the extracellular matrix molecules ECM. Fibroblasts only appear at the lesion site from the third day onwards, after leukocytes have cleansed the injured area. The primary role of fibroblasts is to synthesize collagen. Collagen is the substance responsible for the support and tensile strength of the scar. The rate of collagen synthesis declines approximately after 4 weeks and balances with the rate of degradation, after which the collagen maturation phase begins that, continues for months or even years. TGF-b has a significant role in wound healing. It stimulates type I collagen transcription and inhibits collagenase transcription in fibroblasts. TGF-b is overproduced by keloid tissue, so the excess collagen present in keloid scars may result from overexpression of TGF-b and decreased collagen degradation $[6,8]$.

\section{Remodelling or maturation phase}

An excess of unstable collagen, which produced during the proliferative phase, is degraded and replaced by stable collagen. The former has disorderly manner, while the latter has orderly alignment according to tension forces of the skin. This does not only decrease the size of the scar but also increases its tensile strength. The maximum tensile strength is achieved at 42 days after injury. The maturation phase persists for as long as the wound exists, although the increase in tensile strength stabilizes after 1 year in $70-80 \%$ of the area of intact skin. There is a balance between production and degradation of collagen fibers during this period, through the activity of collagenase. The final maturation phase of wound healing may be implicated in keloid scars, due to an imbalance between the synthesis and degradation of collagen. During normal wound healing, interferon-g (IFN-g) has been shown to inhibit proliferation of fibroblasts and production of ECM macromolecules. IFN-g down-regulates collagen synthesis and increases collagenase synthesis. Reduced production of IFN-g has been reported in patients with keloids $[6,8]$.

The process by which keloid develop is poorly understood, but it is known to be induced by abnormal wound healing in predisposed individuals. There are several theories of keloid etiology, most of them are related to fibroblast dysfunction. Keloid fibroblasts, when compared with fibroblasts isolated from a normal wound, excessive deposition of extracellular matrix components, especially collagen, fibronectin, elastin, proteoglycans. In addition, these cells have higher rates of mitosis, and lower rates of apoptosis. [6,9,10,11] There are several theories of keloid formation according to induced factor. Some of them implicate certain cytokines, other implicate keratinocyte. In contrast, some theories suggest that fibroblasts have the initial disorder.

\section{The following are the most important theories}

Transforming growth factor beta (TGF-b) plays a central role in wound healing and fibrosis and has been implicated in the pathogenesis of keloid. Keloid fibroblasts have been shown to make elevated levels of TGF-b, a growth factor known to stimulate growth and collagen secretion and are thought to be integral to keloid formation [12-14].

Vascular Endothelial Growth Factor (VEGF) and Connective Tissue Growth Factor (CTGF) are overexpressed in keloid tissue and may have a potential role in its evolution [14].

Platelet-Derived Growth Factor (PDGF) is known to stimulate 
the proliferation of connective tissue. High expression of PDGFreceptor in fibroblasts derived from keloid, maybe contribute to the formation of keloid [15]. Also, insulin-like growth factor-1 receptor (IGF-IR) may be involved in the pathogenesis of keloid [16].

Some authors indicated that the excessive scar formation in keloids may be a result of reduced apoptosis of fibroblasts, which may lead to an imbalance between collagen synthesis and degradation. Keloid lesions were found to have lower rates of apoptosis than normal skin, because downregulation of apoptosis-related genes, including p53 [6,9,11,17].

Expression of connexins and other constituent proteins of gap junctions along with gap junctional intercellular communication are involved in cellular development and differentiation processes. Some studies suggest that the loss of gap junctional intercellular communication and connexin expression may affect intercellular recognition and thus break the proliferation and apoptosis balance in fibroblasts derived from keloid tissue $[18,19]$.

However, some studies suggest that keloid fibroblasts may be normal, but they receive abnormal signals from neighboring cells: (a) Maybe there is a role of keratinocyte of keloid formation; some studies suggested that keratinocytes contribute to keloid scarring by regulating extracellular matrix production in fibroblasts [20]. Others showed fundamental abnormalities in keloid keratinocytes, suggesting they have a profoundly more direct role in keloid scarring than previously appreciated [21]. The present of red cell antigens on the membrane surface of red blood cells and certain epithelial cells maybe contribute to keloid formation [22]. (b) Mast cells enhance scar formation, and that these cells may mediate the transition from scar less to fibrotic healing during fetal development [23]. (c)-Recent evidence has indicated the role of type of immune response in keloid formation. Th- 1 is stimulated in normal wound healing, while Th- 2 is stimulated in keloid formation. INF-y and IL-12, which produced from Th1, inhibit proliferation of fibroblasts, while IL-4, IL-5, IL-10 and IL-13, which produce from Th-2 has strongly link to fibrogenesis [23-25].

\section{Epidemiology and Etiology (Risk factors of keloids)}

Several factors play a significant role in keloids formation (Figure 1). The genetic predisposition is the most important factor; other factors are blood groups, melanin, the anatomical site, the type of skin injury, the age of onset, and sex [17].

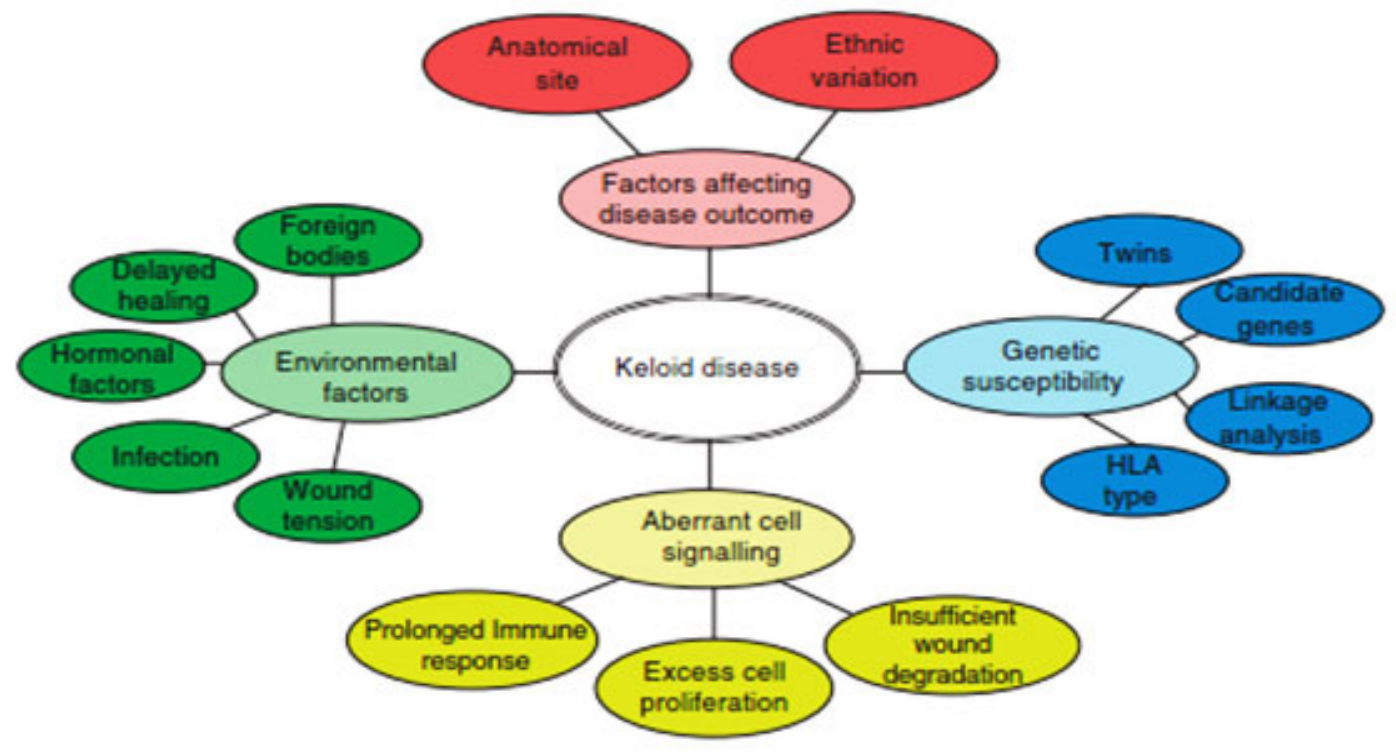

Figure 1: Some of possible causative factors in keloid pathogenesis (6)

\section{Genetic predisposition}

There is a clear genetic component given the correlation with family history, which supported by the following phenomena: (a) some patients with keloids report a positive family history [5,26]. $19.3 \%$ of Syrian patients had a family history, $50 \%$ of Afro Caribbean patients, and $36.4 \%$ of Nigerian patients [27-
29]. (b) high occurrence in identical twins [26,28,30]. (c) Higher predisposition in Blacks, Hispanics and Asians, less frequently in Caucasians [28]. (d) Increased incidence of keloids in patients with some genetic syndromes like Turner syndrome, OpitzKaveggia syndrome, Rubinstein Taybi syndrome and Ehlers Danlos syndrome [31,32]. 
Proposed inheritance patterns include autosomal recessive, autosomal dominant with incomplete penetrance, and variable expression $[4,26]$. Several genes are considered responsible for keloid disease, but no single gene mutation has thus far been found to be responsible [32]. Genome wide association studies in Japanese population have shown that four SNP (single nucleotide polymorphism) loci in three chromosomal regions (1q41, 3q22.3-23 and 15q21.3) exhibit significant associations with keloids [33]. Marneros and colleagues studied two families with an autosomal dominant inheritance pattern of keloids (Japanese family and African American one). they identified linkage to chromosome 2q23 (maximal two-point LOD score of 3.01) for the Japanese family. The African-American family showed evidence for a keloid susceptibility locus on chromosome 7p11 (maximal two-point LOD score of 3.16) [34]. Brown and colleagues found a genetic association between HLA-DRB1*15 statuses and the risk of developing keloid scarring in white individuals [35]. Also, carriers of HLA-DQA1*0104, DQB1*0501 and DQB1*0503 have been reported to be have an increased risk of developing keloid scarring [5].

There is importance of the cause and anatomical site in heredity of keloid. $76 \%$ of patients with family history have keloids located in the same anatomical sites of the relative, and $66 \%$ of them have keloids caused by the same cause [27]. Also, there is predisposition to heredity spontaneous keloids, which usually appears in the second decade, and for heredity presternal and shoulder keloids [27]. In addition, family history is strongly associated with the formation of keloid scars in multiple sites as opposed to a single anatomical site $[4,28,36,37]$.

\section{Blood groups}

People with blood group A have high probability to develop keloids compared with other blood groups, that may be partly explained by the association between the effect of red cell antigens A (which present on the membrane surface of red blood cells and certain epithelial cells) and other factors in these patients $[22,27,30]$. A study by Shaheen revealed association between spontaneous keloids and blood group A ( $p=0.01)$, which confirms the effect of red cell antigens $\mathrm{A}$ in development of keloids [27]. (This finding has not been previously reported).

\section{Melanin}

There is a relationship between keloid formation and skin color, as supported by the following phenomena: (a) Colored skin people such as the Negroid and Mongoloid races have a greater tendency to suffer from keloid compared to the Whites (the Caucasian race). The comparative ratio between Blacks and Whites who suffer from keloid varies extensively, ranging from 5 up to 18.7 to one. On the other side, evidently keloid is not found among albino which is a condition where there is absent or minimal melanin pigment [8,28,38-40]. (b) The incidence of pathological scarring varies across different parts of the body even in the same individual; for example, fewer keloids develop in the palm and thenar eminence, where melanocytes are less common [14,38]. (c) Adolescents and pregnant women, who are subjected to increased hormone secretion and skin pigmentation, are more susceptible to developing keloids [38]. Based on these facts, it becomes apparent that the incidence of keloid is strongly related to skin color. Melanin is the most important pigment which determines variations in skin color of the various races in the world [38,41].

The relationship between melanin and keloid formation have been assumed by several theories: (a) During wound healing, melanocytes from the stratum basal contact or interact with fibroblasts from the dermal layers after the basal membrane is damaged, which in turn facilitates fibroblast proliferation and the secretion and deposition of collagen [38]. (b) High levels of melanin cause decreasing of histologic $\mathrm{PH}$, which inhibit collagenase, that disrupts collagen degradation process [41].

\section{Anatomical site}

Several studies indicated to the role of anatomical site in keloid formation, which supported by the following phenomena: (a) genetically susceptible individuals form keloids after wounding but not at everybody site [28]. (b) Generally keloids tend to occur on highly mobile sites with high tension such as shoulders, neck, and presternum $[3,42]$. (c) There are familial patterns of keloid distribution [4].

Anterior chest, shoulders, earlobes, upper arms and cheeks have a higher predilection for keloid formation. Eyelids, cornea, palms, mucous membranes, genitalia and soles are generally less affected [5]. The most common anatomical site for developing keloids differs according to race, traditions and conditions of study's society. Shaheen indicated that upper limb $20 \%$ followed by sternum $19.17 \%$ were the most common sites for developing keloids in Syrian patients [27]. Similarly, Abas Mouhari Toure noted that sternum $28.95 \%$, upper limb $15.8 \%$ and head 16.7 $\%$ were the most common sites in dark skin patients [43]. Conversely, ear $23 \%$ was the most common one in Bayat's study [27]. On other hand, most of studies agree that genitalia, buttock, palm and sole are the rarest sites for developing keloids [2729,43].

keloids could develop at any anatomical sites, but there is association between type of skin injury and specific anatomical sites. Syrian study found that $80 \%$ of spontaneous keloids were located on sternum and shoulders, these agree partly with a previous study, which demonstrated that sternum was the most common site for spontaneous keloids $[27,44]$. Also, $45 \%$ of burn keloids were located on extremities (lower and upper) in that study, while a Japanese study found that all burn keloids were located on chest wall and lower limbs $[27,45]$. About $40 \%$ of sharp wound keloids were located on upper limbs, and $50 \%$ of surgical keloids were located on sternum and abdominal wall $[27,45]$. Sternum and shoulder are the most common site for acne keloids. Syrian study found that about half of acne keloids were located in these sites, while most acne keloids were located in these sites in the Japanese study [27,45]. 37\% of trauma keloids were located on face and upper limb in Syrian patients, which agree partly with the Japanese study, which found that most trauma keloids were located on extremities (upper and lower) [27,45]. 
Few studies discussed the development of keloids in single versus multiple anatomical sites and its correlation with patient's clinical feature and prognosis [28,37]. Shaheen found that 19.3 $\%$ of patients had keloids in multiple anatomical sites, where upper limb was the most common site for developing keloids in them $46 \%$, and burn was the most common cause $38.2 \%$. Bayat demonstrated that $42.2 \%$ of patients had keloids in multiple anatomical sites, where earlobe was the most common site in multiple $24 \%$ sites, and ear piercing was the most common cause $[27,28]$. Although all causes tend to develop keloids in multiple sites, only burn and acne have association with developing keloid in multiple sites in Syrian patients $(p=0.029)(p=0.0002)$ respectively, which means there is high probability to develop acne or burn keloids in another anatomical site in a patient who had a previous acne or burn keloid respectively, because both acne and burn could affect multiple sites more than other causes, which is more located [27]. Female sex, younger age at presentation and the presence of a positive family history are associated with the development of keloid scars in multiple anatomical sites in Afro Caribbean individuals [28].

\section{Causes of keloids (type of skin injury)}

Keloids may develop following any skin insult like burn, trauma, surgery, piercings, acne, vaccinations ... , but not all such insults lead to a keloid scar even in the susceptible individuals $[5,28]$. This means all types of skin injuries could cause keloids, but each patient is affected by specific type of injuries. That indicates to the role of type of skin injury in keloid formation, which supported by the higher prevalence of single keloid more than multiple keloids, although the patient is exposed to other injuries that may cause keloid. On other hand, there are very few patients have keloids caused by two different causes [43].

The most common cause of keloid differs according to conditions of study's society. Syrian and Iranian studies found that keloids could follow any form of skin injury, but burn was the most common $[27,46]$. Bayat found that laceration was the most common cause in Afro Caribbean patients [28]. Causes have almost coordinated distribution in males and females, but males have higher predisposition to develop acne keloids compared to female, because only males have acne keloidalis nuchae, and the severity of acne is higher in them [27].

Spontaneous keloid is a rare condition, and it is controversial whether it is in fact spontaneous. The scar tissue may form after an insignificant inflammatory reaction or injury which the patient has no recollection of [47]. Syrian study found $13.4 \%$ of spontaneous keloids, which was similar to Togo study $13.13 \%$, but lesser than an Iraqi one $34 \%[27,43,48]$. As we said before, some patients have hereditary of spontaneous keloids, while others have association with blood group A [27]. There is confirmed evidence of the association between spontaneous keloid formation and different diseases such as Dubowitz syndrome, Rubenstein-Taybi syndrome, and Noonan syndrome [36]. In addition, Spontaneous keloid has been reported in siblings and in people with allergic disease [49]. There are very few patients have keloids caused by two different causes [27]. They are only
$2.32 \%$ of patients in Syrian study, $83.3 \%$ of them had surgical keloids, so we have to be careful when performing surgery for a patient who had a previous keloid [27]. On other hand, this percentage is higher in dark skin patients $15.9 \%$, maybe because developing keloid is more common in Blacks than in Whites [43].

keloids could follow any skin insults, but there is association between anatomical sites and specific injuries. Shaheen found that burn was the most common cause of keloid formation in uncovered sites (face (35\%), neck (50\%), upper limbs (44.29\%, lower limbs (66.66\%), and chest wall (27.59\%)),) and less affected sites (lower back (37.5\%), button $(50 \%)$, genitalia (50\%), palm and sole $(66.66 \%)$ ), which disagree partly with the Japanese study, found that trauma was the most common cause of extremities keloids [27,45]. Ear piercing is the most common cause for earlobe keloid $[27,28,45]$. Acne is the most common cause for scalp keloids $[27,28]$. More than quarter of shoulder keloids were caused by acne $[27,45]$. The Syrian study found that Most sternum keloids were spontaneous (35.82\%), or followed surgery $(37,13 \%)$, while most sternum keloids were caused by trauma in Jamaican study, or acne in Japanese study $[27,28,45]$. At last, abdominal keloids followed by surgery in several study, more than half of abdominal keloids followed surgery in the Syrian study, while all abdominal keloids followed surgery in the Japanese study [27,45].

A previous study reported that $1.93 \%$ of patients have keloids caused by two different causes, and distributed on multiple anatomical sites. This maybe indicates that very few people have a high predisposition to develop keloids, but this finding needs more research [27].

\section{Age of onset}

Although keloids could occur at any age, they are rare in first decade, because people in this decade are not stimulated by sexual hormones (higher incidence of keloid formation during puberty) $[5,8,27]$. Most likely to occur in second and third decades and tend to decrease in older $[27,28,30,38]$, which supported by the following phenomena: (a) younger people may have a higher frequency of trauma, their skin is more elastic than the skin of elderly people [50], (b) they have higher level of sexual hormone than older people (Keloid growth may also be stimulated by various hormones, as indicated by some studies in which results have suggested a higher incidence of keloid formation during puberty and pregnancy, with a decrease in size after menopause) $[5,8,14,27]$. Also, younger age is associated with the development of keloid scars in multiple anatomical sites [28]. Each decade has preference to develop keloids in specific site, following specific cause. Burn is the most common cause for developing keloids in first decade compared with other decades, especially on upper and lower limbs. This is a logical result, because most of burn accidents exist in younger children especially on extremities [27]. Occurrence of acne keloids is higher in second decade compared with other decades, because the peak in prevalence and severity of acne occurs in second decade. High frequency of sharp wound accidences and earlobe piercing in second decade explain the higher incidence of these keloids in this decade [27]. Also, 
development of scalp keloids is higher in second decade compared with other decades, because most cases of acne keloidalis nuchae occur in persons aged 14-25 years (most cases of scalp keloids are caused by keloidalis nuchae) [27]. There is absence of acne keloids in fourth decade, because frequency of acne extremely decreases in this decade [27]. At last, development of surgical keloids is higher in fifth, sixth and seventh decades compared with other decades, especially on sternum. These results reflect an increase of open heart surgeries in older people, especially for males who are older than forty compared to females in the same age [27].

\section{Sex}

Incidence of keloids is usually equal in females and males $[30,43,48,50]$, but sometime there is higher incidence in female $[28,50]$ (it could be related to the higher rate of earlobe piercing in females), or in male (it could be related to acne keloidalis nuchae, especially in Blacks) [29]. In general, both sexes develop keloids in the same anatomical sites, and followed to the same injuries, but sometimes there is preference for one gender to develop keloids in specific site, following specific cause, at specific age. Males who are older than forty could develop keloids more than females in the same age (as we will discuss later). Also, males have higher predisposition to develop acne and scalp keloids compared to female, because only males have acne keloidalis nuchae, also, the severity of acne is higher in them [27]. Females have higher incidence of earlobe keloids than males [28,50], because ear piercing is more common in females. As we said before, Female sex are associated with the development of keloid scars in multiple anatomical sites in Afro Caribbean individuals $[28,37]$.

Note: the above risk factors are unmodifiable factors, but there are modifiable factors like delayed healing, and hypertension $[51,52]$.

\section{Delayed healing}

This usually occurs as a result of wound infection or if wound edges are not opposed. This will lead to healing by second intention as the defect fills gradually with granulation tissue and restoration of epidermal continuity may take a considerable time. Healing by second intention usually results in prolonged healing, excessive fibrosis and an ugly puckered scar as opposed to healing by first intention which occurs following the meticulous apposition of the edges of clean incised skin. This leaves a narrow epidermal defect which can be bridged easily resulting in a fine hairline scar. Thus healing by second intention is more likely to develop keloids especially if healing time is greater than three weeks [51].

\section{Hypertension}

There is relationship between hypertension and development of severe keloids. Blood pressure associated significantly and positively with both keloid size and number (both $\mathrm{p}<0.0001$ ). This association may reflect the fact that hypertension damages blood vessel, thereby increasing inflammation in local tissue [52].

\section{Diagnosis}

It is based on clinical features, but sometimes we need histopathology.

\section{Origin}

Keloids manifest as exaggerated growths of scar tissue, usually in areas of previous trauma. Keloids extend past the areas of trauma, projecting above the level of the surrounding skin, but they rarely extend into underlying subcutaneous tissue $[5,53]$.

\section{Origin}

Keloids are nodular tumors range in consistency from soft and doughy to rubbery and hard, and have shiny and soft surfaces. Lesions are usually devoid of hair follicles and other functioning adnexal glands. In the Caucasian patient, keloids tend to be erythematous and telangiectatic; they are often hyperpigmented in darker-skinned individuals. Early lesions are often erythematous, then they become brownish red and then pale as they age. Once lesions occur, the clinical course varies. Most lesions continue to grow for weeks to months and others grow for years. Growth is usually slow, but keloids occasionally enlarge rapidly, tripling in size within months. Keloids on the ears, neck, and abdomen tend to be pedunculated. Keloids on the central chest and extremities are usually raised with a flat surface, and the base is often wider than the top (Figure 2,3). Most keloids are round, oval, or oblong with regular margins; however, some have clawlike conFigureurations with irregular borders. Keloids overlying a joint can contract and restrict movement (Figure 4,5) $[5,53]$.

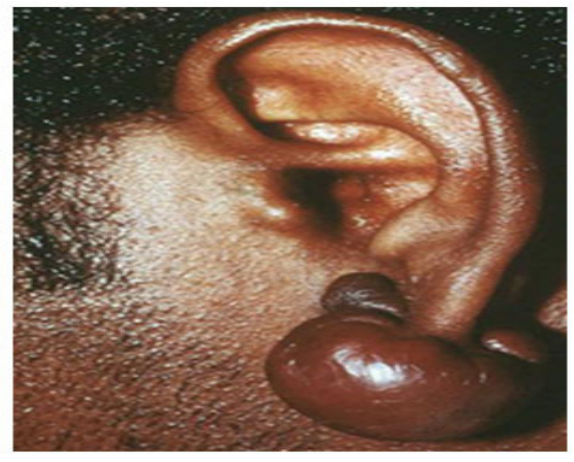

Figure 2: Pedunculated keloid on earlobe (50)

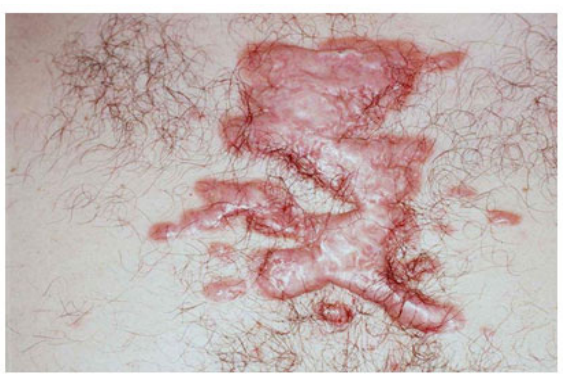

Figure 3: Sessile keloid on chest (50) 


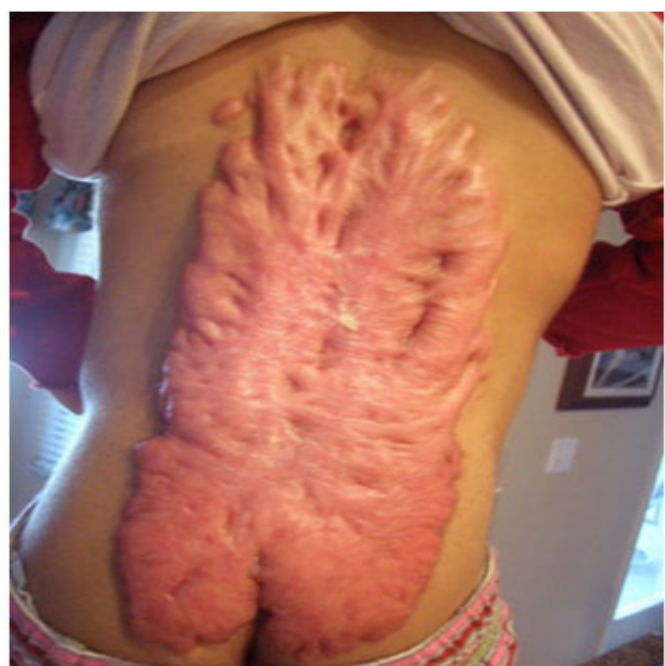

Figure 4: Expanded keloid

\section{Symptoms}

Keloids may be symptomless, but they are often pruritic hyperesthesia and $\backslash$ or painful, in addition to significant effects of patient's quality of life, both physically and psychologically, especially in excessive scarring. Once they stop growing, keloids do not usually cause symptoms and remain stable or involute slightly $[5,53]$.

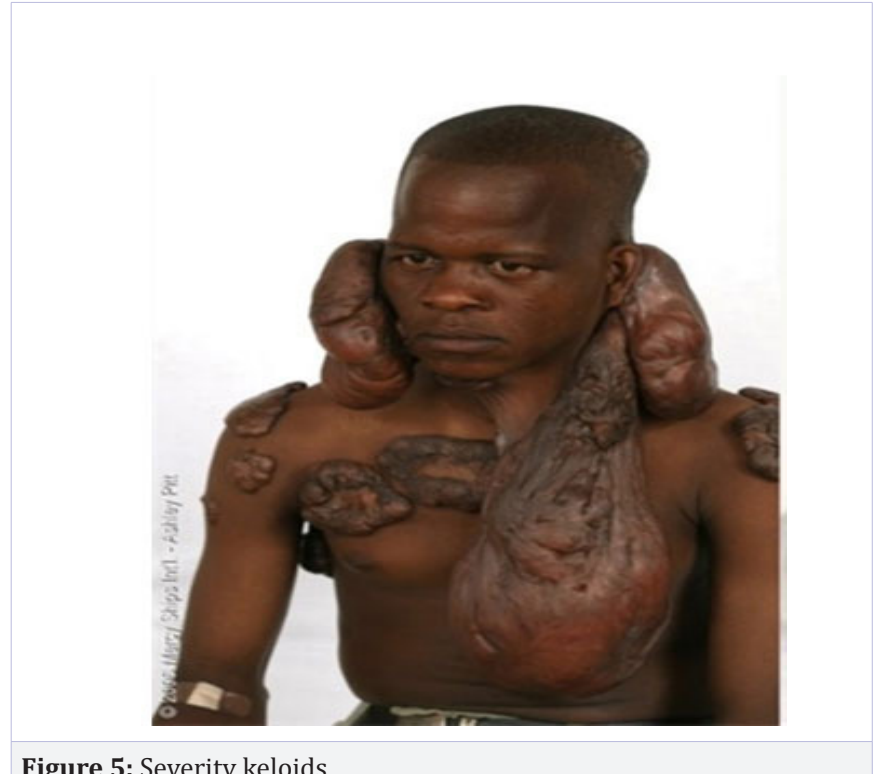

Figure 5: Severity keloids

\section{Differential diagnoses}

\section{Hypertrophic scars}

The main differential diagnosis of keloid is hypertrophic scar, also called pseudokeloid. Differential diagnosis is important, since treatment a procedure differs between these two types of scar disorders. The (Table-1) and (Figure 6,7) below didactically describes the clinical differences between them $[5,8]$.

Table 1: the difference between keloid and hypertrophic scars

\begin{tabular}{|c|c|c|}
\hline & Keloid & Hypertrophic scar \\
\hline Heredity & Some patients have positive family history & No family history \\
\hline Race & Blacks more than Whites & No predisposed race \\
\hline Sex & Equal & Equal \\
\hline Age & Second and third decades & Second and third decades \\
\hline Extension & Spreads beyond the margin of the original wound & $\begin{array}{l}\text { Remained within the boundaries of the } \\
\text { original lesion }\end{array}$ \\
\hline Anatomical site & $\begin{array}{l}\text { Any anatomical sites, especially with high tension (joints), } \\
\text { such as knees and ankles. }\end{array}$ & $\begin{array}{l}\text { Anterior chest, shoulders, earlobes, upper } \\
\text { arms and cheeks }\end{array}$ \\
\hline Causes & The exact cause is unknown & Related to tension on the wound. \\
\hline Incidence & $6 \%$ to $16 \%$ in African populations. & $\begin{array}{l}\text { Vary from } 40 \% \text { to } 70 \% \text { following surgery to } \\
\text { up to } 91 \% \text { following burn injury, depending } \\
\text { on the depth of the wound. }\end{array}$ \\
\hline Evolution & $\begin{array}{l}\text { May develop up to several years after minor injuries, } \\
\text { persist usually for long periods of time, and do not } \\
\text { regress spontaneously. }\end{array}$ & $\begin{array}{l}\text { Usually occurs within } 4 \text { to } 8 \text { weeks following } \\
\text { wound, has a rapid growth phase for up to } 6 \\
\text { months, and then gradually regresses over a } \\
\text { period of a few years. }\end{array}$ \\
\hline Response to surgery & Poor, with possible worsening & Good, especially with adjuvant therapy. \\
\hline Contractures & Not present & Present \\
\hline Appearance & Have clawlike configurations & No clawlike configurations \\
\hline Itch - Erythema & Yes & Yes, but rare \\
\hline
\end{tabular}




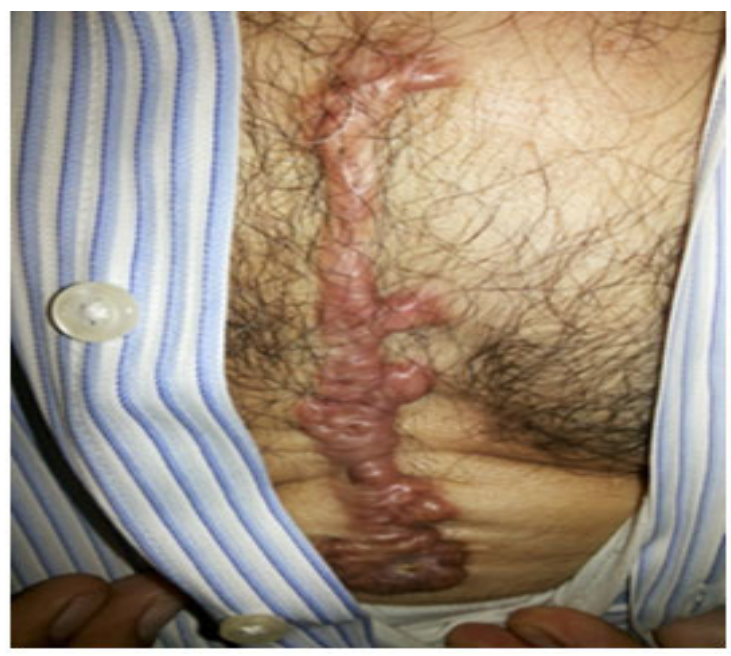

Figure 6: Keloid

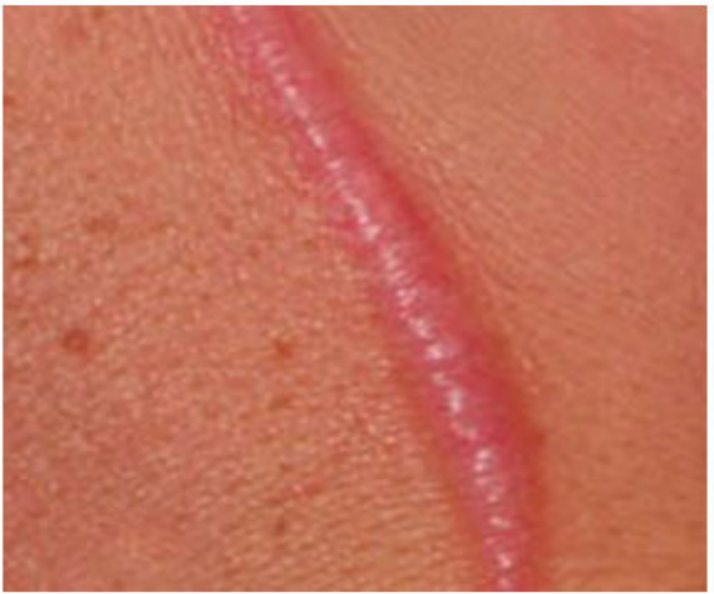

Figure 7: Hypertrophic scar

\section{Dermatofibroma (superficial benign fibrous histiocytoma)}

It is a common cutaneous nodule of unknown etiology that occurs more often in women. Dermatofibroma frequently develops on the extremities (mostly the lower legs) and is usually asymptomatic, although pruritus and tenderness can be present It is actually the most common painful skin tumor. Removal of the tumor is usually not typically required unless diagnostic uncertainty exists or particularly troubling symptoms are present [53] (Figure 8).

\section{Lobomycosis (lacaziosis)}

It is a self-limited, chronic fungal infection of the skin endemic in rural regions in South America and Central America [53] (Figure 9).

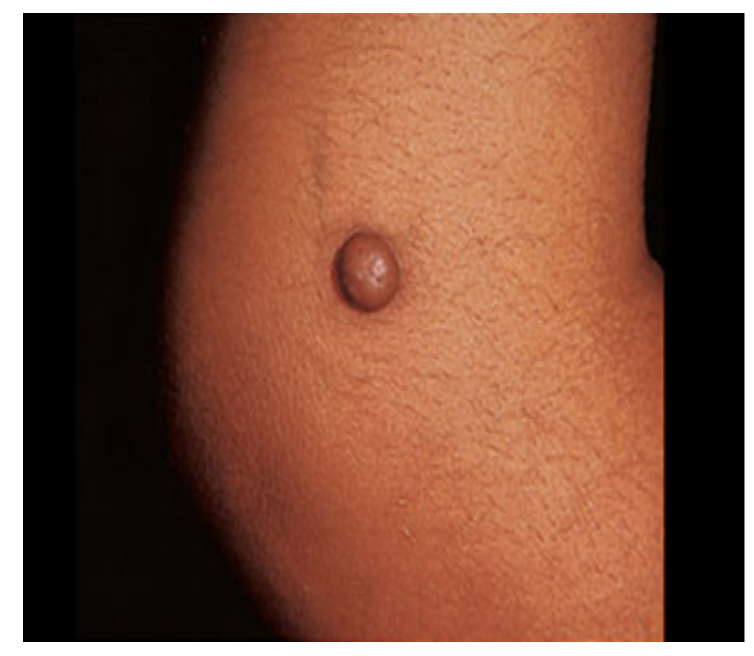

Figure 8: Dermatofibroma
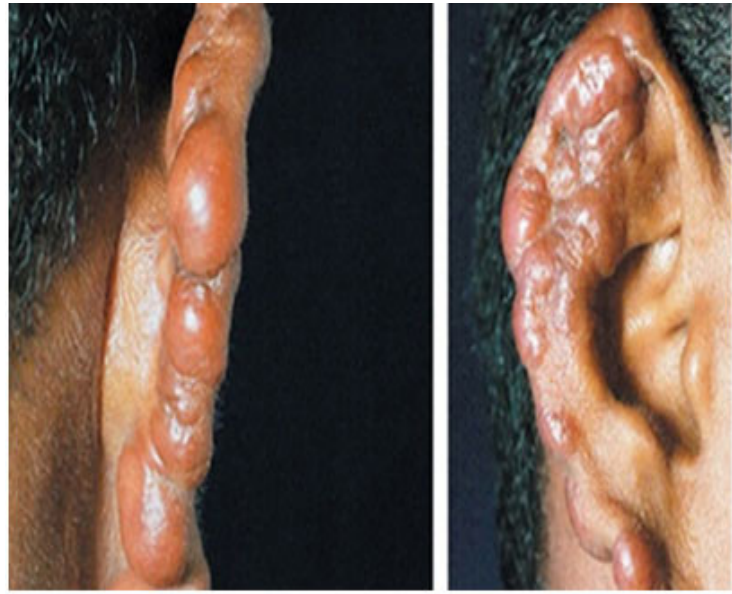

Figure 9: Lobomycosis

\section{Other D.D}

A previous study suggested the presence of various kinds of malignant tumors that resemble keloid or hypertrophic scar, including dermatofibrosarcoma protuberans, trichilemmal carcinoma, and keloidal basal cell carcinoma [54].

\section{Histopathology}

Different diagnosis between keloid and hypertrophic scar is not only a clinical challenge, but also histological challenge. We will review histological differences between keloid and hypertrophic scar for accurate diagnosis [55]. Hematoxylin eosin is used in histological study.

\section{Epidermal changes}

(a) Flattening of epidermis: is more common in hypertrophic scars (Figure 10) and less common in keloid. (b) Hyperkeratosis and hypergranulosis: are consistent features 
in all types of keloid scars, hypertrophic scars and normal scars (c) Spongiosis: is mostly apparent in keloid. (c) Basal cell organization: is order in keloids, and disorder in hypertrophic scars (Figure 11). (d) Basal cell vacuolar change: is diffusely prominent in the keloid scars (Figure 12), but less common in hypertrophic scars and normal scars. The presence of basal cell vacuolar change in the keloid group correlated with the added presence of spongiosis in all of these cases.

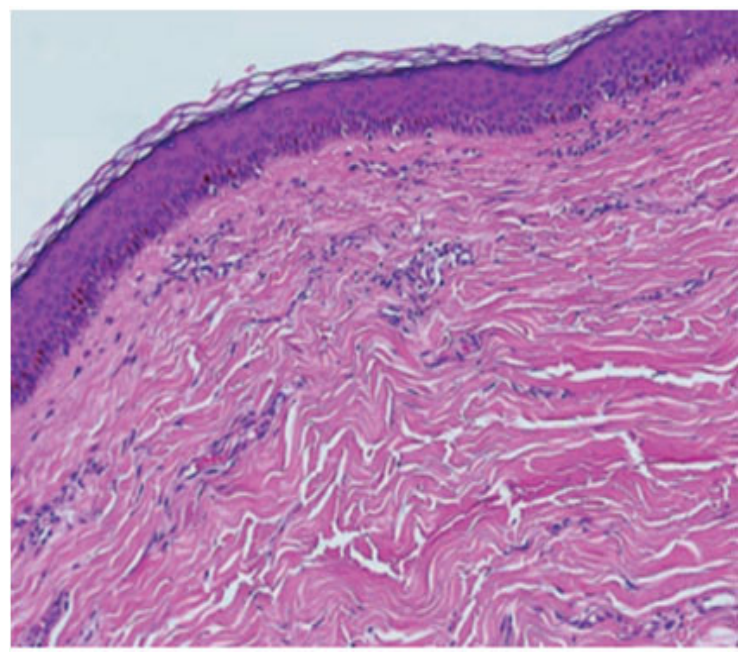

Figure 10: Hypertrophic scar $20 \mathrm{X}$ showing epidermal flattening with scarring of papillary dermis and horizontally oriented wavy collagen fibers (52)

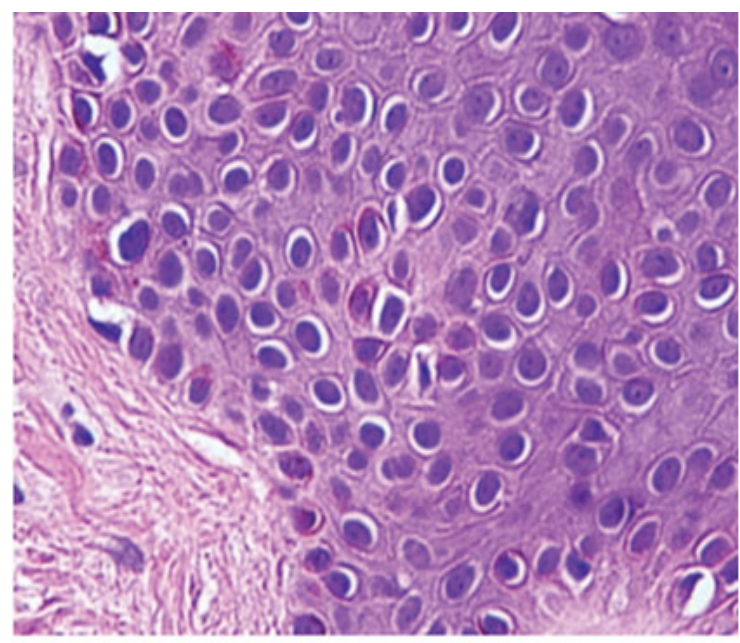

Figure 11: Hypertrophic scar $40 \mathrm{X}$ showing epidermal disarray (52)

\section{Dermal changes}

(a) Scarring of papillary dermis: : is very prominent in all hypertrophic scars, frequent in keloids, and normal scars. (b) Collagen distribution: collagen is seen spanning full thickness of the dermis including the papillary dermis in all keloid scars, while it remains confined to the upper one third of reticular dermis in all hypertrophic scars. The normal scars collagen is confined to

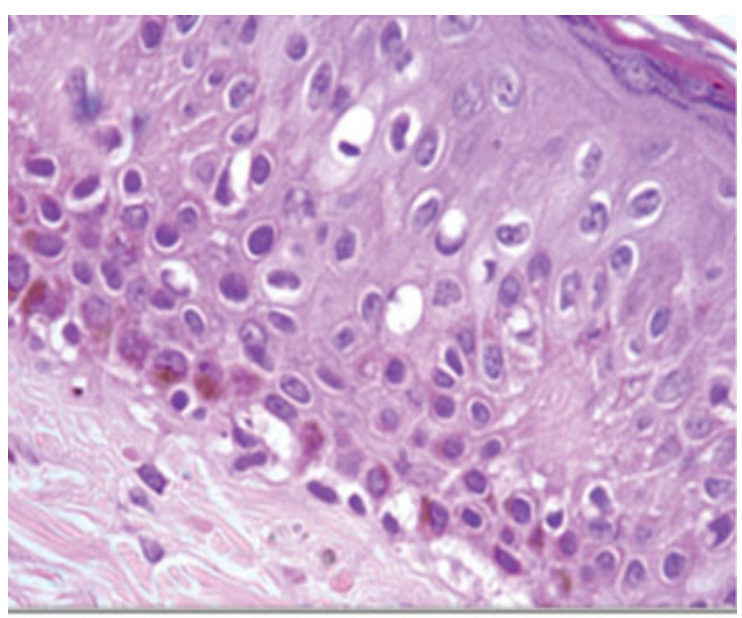

Figure 12: Keloid scar $40 \mathrm{X}$ showing basal cell vacuolar change (52)

the upper half of the reticular dermis. (c) Collagen fibers: keloids have abnormal, dense, broad, glassy, eosinophilic, and arranged haphazardly collagen bundles (Figure 13). (d) These collagen bundles associate with variable amounts of extracellular myxoid matrix in keloids. On the other hand, the collagen in hypertrophic scars is discretely nodular, fibrillar with fairly regular fiber thickness having their long axis parallel to the epidermis with no extracellular myxoid matrix (Figure 14). The collagen in normal scars is wavy, delicate and parallel to the long axis with no extracellular myxoid matrix. (e) An advancing edge below the epidermis is present in most keloids (Figure 15), and absent in all hypertrophic and normal scars. (f) Blood vessels: are seen aggregating below the epidermis in all keloids with a tendency of growing towards the epidermis, are vertically oriented around the nodules in the hypertrophic scars as compared to the horizontal orientation in normal scars. (g) Chronic inflammatory infiltrate: is of moderate degree in all keloids, and locates perivascular in location with scattered mast cells (Figure 16). About fifth of hypertrophic scars show mild perivascular chronic inflammatory infiltrate in with scattered mast cells.

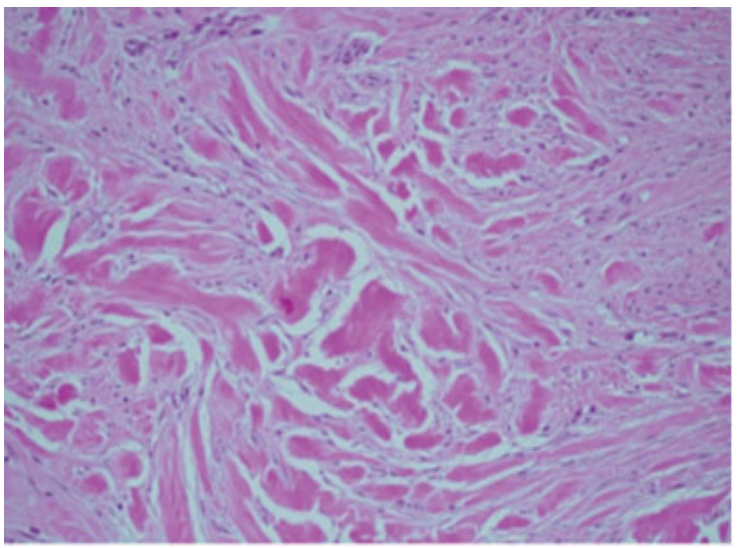

Figure 13: Keloid showing abnormally large dense, broad, glassy, eosinophilic, focally fragmented complexes, arranged haphazardly (52) 


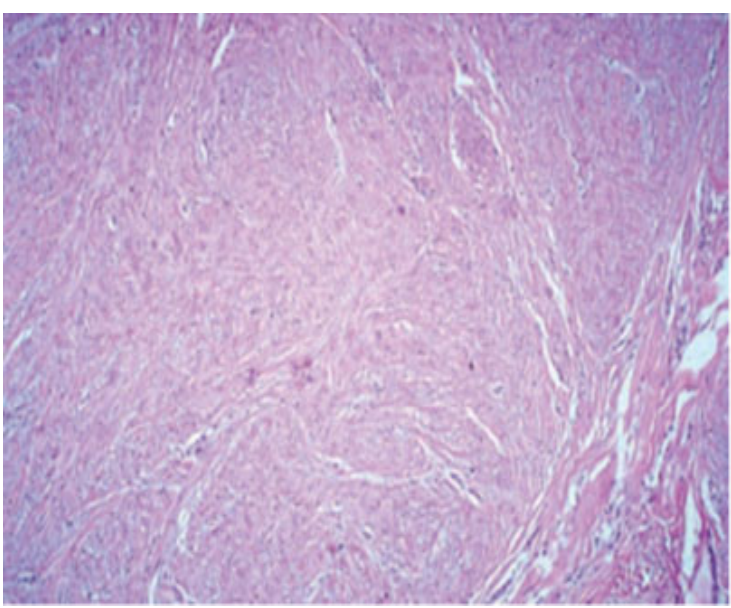

Figure 14: Hypertrophic scar showing nodules of fibrillary collagen of fairly regular thickness (52)

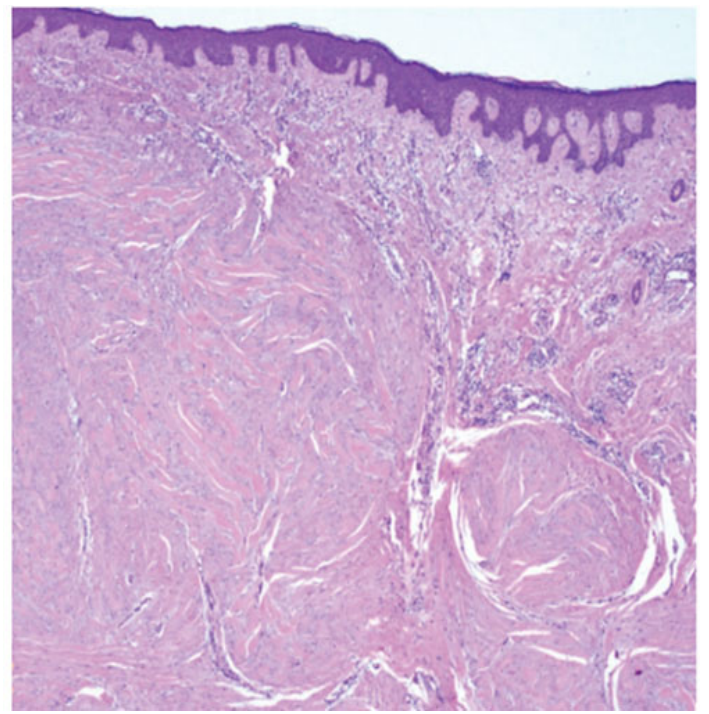

Figure 15: Keloid scar 20X showing advancing edge below the epidermis (52)

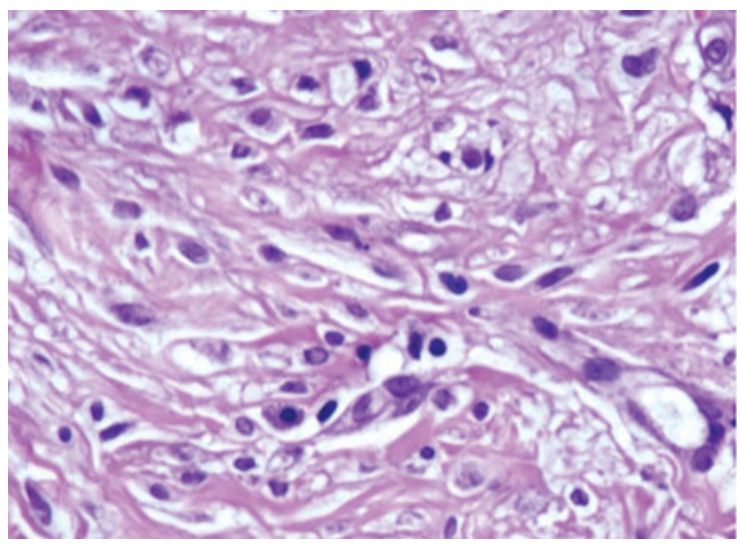

Figure 16: Keloid scar $40 \mathrm{X}$ showing chronic inflammatory infiltrate and mast cell (52)

\section{Treatment}

No single therapeutic modality is best for all keloids. The location, size, and depth of the lesion; the age of the patient; and the past response to treatment determine the type of therapy used. We will review several options in keloid treatment.

\section{Standard Treatments}

These include occlusive dressings, compression therapy, and intralesional corticosteroid injections

Occlusive dressings include silicone gel sheets and dressings, nonsilicone occlusive sheets, and cordran tape. These measures have been used with varied success. Antikeloidal effects appear to result from a combination of occlusion and hydration, rather than from an effect of the silicone. More than 60 products have been marketed, including silicone sheets (Figure 17,18), strips, gels, sprays, and foams. To be effective, sheets must be worn over the scar for 12 to 24 hours per day for two to three months. The sheet and the scar should be washed daily with mild soap and water. The sheets can be reused until they start to disintegrate. There is variation in the success rate of these treatments; a previous study has shown that in patients treated with silicone occlusive sheeting with pressure worn $24 \mathrm{~h} / \mathrm{d}$ for up to 12 months, 34\% showed excellent improvement, $37.5 \%$ showed moderate improvement, and $28 \%$ demonstrated no or slight improvement. Another study has shown that in patients treated with semipermeable, semiocclusive, nonsilicone-based dressings for 8 weeks, $60 \%$ experienced flattening of keloids, $71 \%$ had reduced pain, $78 \%$ had reduced tenderness, $80 \%$ had reduced pruritus, $87.5 \%$ had reduced erythema, and $90 \%$ were satisfied with the treatment. Cordran tape is a clear surgical tape that contains flurandrenolide, a steroid that is uniformly distributed on each square centimeter of the tape, and it has been shown to soften and flatten keloids over time $[53,56,57]$.

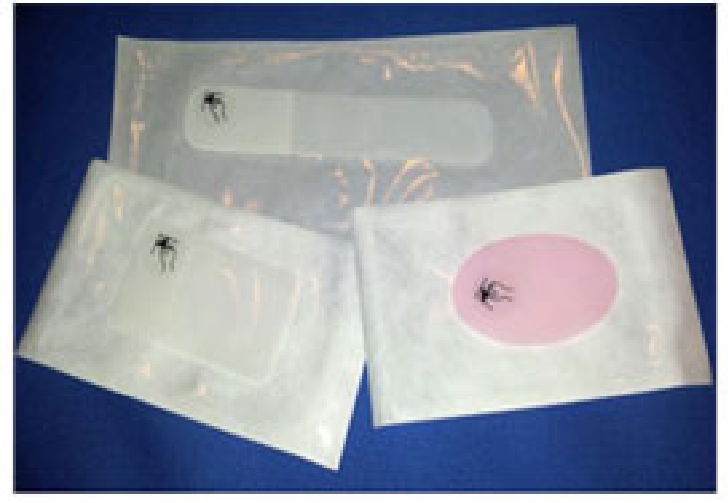

Figure 17: Silicone sheets

Compression therapy involves pressure, which has long been known to have thinning effects on skin. Reduction in the cohesiveness of collagen fibers in pressure treated hypertrophic scars has been demonstrated by electron microscopy. Cellular mechanoreceptors may have an important role of compression therapy. Mechanoreceptors induce apoptosis and are involved 


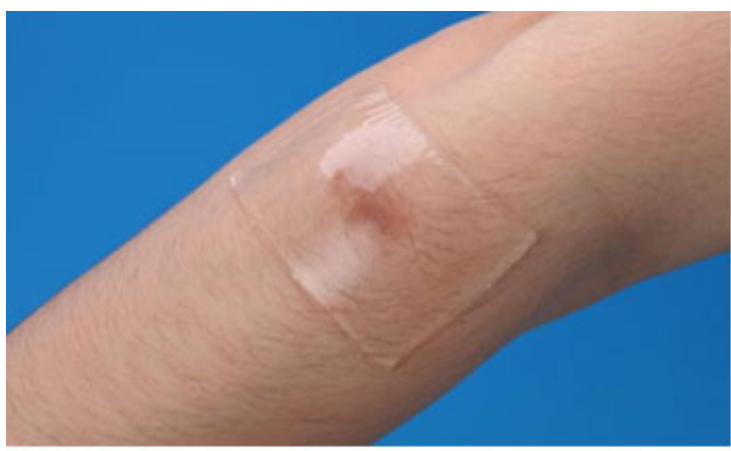

Figure 18: Use silicone sheet

in the integrity of the extracellular matrix. It can be used in the treatment of keloids and in the prevention of hypertrophic scar formation after burn injury. A pressure of $18-24 \mathrm{~mm} \mathrm{Hg}$ is applied for 23 hours and a half of it daily for 6 to 12 months.

Compression treatments include button compression, pressure earrings (Figure 19,20), ACE bandages, elastic adhesive bandages, compression wraps, spandex or elastane (Lycra) bandages, and support bandages. In one study, button compression ( 2 buttons sandwiching the earlobe applied after keloid excision) prevented recurrence during 8 months to 4 years of follow-up observation $[53,58]$.

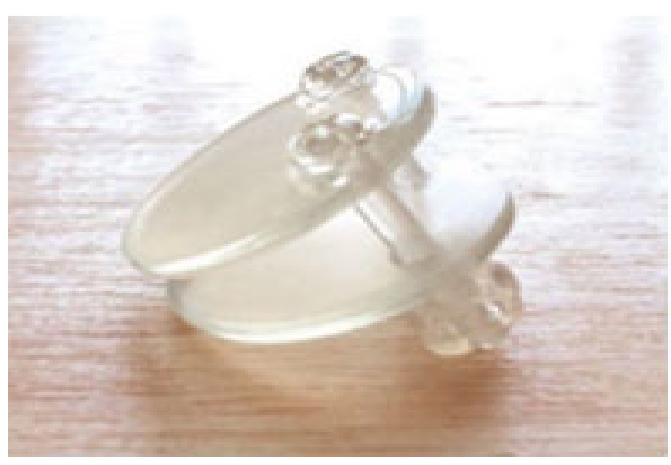

Figure 19: Pressure earring
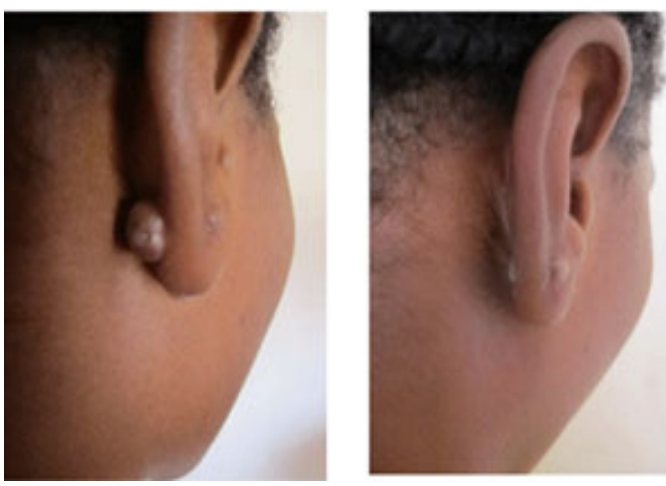

Figure 20: Before and after pressure earring
Corticosteroids, specifically intralesional corticosteroid injections, have been the mainstay of treatment. Corticosteroids reduce excessive scarring by reducing collagen synthesis, and reducing production of inflammatory mediators and fibroblast proliferation during wound healing. The most commonly used corticosteroid is Triamcinolone Acetonide (TAC) in concentrations of $10-40 \mathrm{mg} / \mathrm{mL}$ administered intralesionally at four to six week intervals. Intralesional steroid therapy as a single modality and as an adjunct to excision has been shown to be efficacious in various studies. Response rates varied from $50-100 \%$, with recurrence rates of $9-50 \%$ in completely resolved scars. When combined with excision, postoperative intralesional TAC injections yielded a recurrence rate of $0-100 \%$, with most studies citing a rate of less than 50\%. A standardized corticosteroid therapy protocol has been shown to reduce the recurrence of keloids after excision. Intralesional TAC injection was performed after removal of the sutures and then once every 2 weeks (total of 5 treatments). In addition, patients were instructed to apply corticosteroid ointment twice daily for 6 months to the wounds after suture removal. Complications of repeated corticosteroid injections include atrophy, telangiectasia formation, and pigmentary alteration. Triamcinolone can be combined with 5-fluorouracil (50 mg/ml 5-FU in $10 \mathrm{mg} / \mathrm{ml}$ triamcinolone acetonide). Success rate is about $70 \%[53,59]$.

\section{Cryotherapy}

Cryosurgical media like liquid nitrogen affects the microvasculature and causes cell damage via intracellular crystals, leading to tissue anoxia. Generally, 1, 2, or 3 freezethaw cycles lasting 10-30 seconds each are used for the desired effect. Treatment may need to be repeated every 20-30 days. Cryotherapy can cause pain and permanent depigmentation in selected patients. As a single modality, cryosurgery led to total resolution with no recurrences in $51-74 \%$ of patients after 30 months of follow up observation.

Newer methods of application of liquid nitrogen include the insertion of a lumbar puncture needle through the long axis of the keloid, from one side to the other, passing the liquid nitrogen with an intravenous drip set for 2 freeze thaw cycles of 20-30 seconds each for 5-10 sessions. Flattening was achieved in $75 \%$ of the patients. A single treatment with an intralesional cryoprobe was used to treat 10 earlobe keloids in 10 white patients, obtaining a statistically significant reduction in the scar volume of $67.4 \%$ after 18 months of follow up compared with baseline measurements. Zero recurrences were reported. Other scar parameters also improved [53].

\section{Excision}

Decreased recurrence rates have been reported with excision in combination with other postoperative modalities, such as radiotherapy, injected IFN, or corticosteroid therapy. Excisional surgery alone has been shown to yield a $45-100 \%$ recurrence rate and should very rarely be used as a solitary modality, although excision in combination with adjunct measures can be curative. Most studies in which excisional surgery was combined with injected steroids reported a recurrence rate of less than 
$50 \%$. Surgery followed by adjunctive radiotherapy has obtained recurrence rates of $0-8.6 \%$.

The authors have studied the effects of topically applied imiquimod 5\% cream (Aldara) on the postexcision recurrence rates of 13 keloids excised surgically from 12 patients. Starting the night of surgery, imiquimod 5\% cream was applied for 8 weeks. Patients were examined at weeks 4, 8, 16, and 24 for local erythema, edema, erosions, pigment alteration, and/or recurrence of the keloid. Of the 11 keloids evaluated at 24 weeks, none $(0 \%)$ recurred. Both patients completed the 8 weeks of topical therapy and the final 24 -week assessment. At 24 weeks, the recurrence rate of excised keloids treated with postoperative imiquimod $5 \%$ cream was lower than recurrence rates previously reported in the literature. Side effects are hyperpigmentation, irritation and superficial erosion [53].

\section{Radiotherapy}

Radiation destroys fibroblasts in the wound, prevents neovascularization, which ultimately leads to a decreased production of collagen. Radiotherapy alone has low efficacy in the treatment of keloids, and in combination with surgical techniques the success rate is $80 \%$, the same as with corticosteroid injection therapy. Hyperpigmentation of the skin and carcinogenic effect are side effects of these therapy Oncologic complications are the main contraindication for the use of radiotherapy in the treatment of benign lesions that do not compromise life.

Recurrence is not uncommon, and this technique is unsuitable for young patients as late side effects of radiotherapy may develop. When excisional surgery is followed by postoperative radiation treatment, the total fractionated dose should be a minimum of $12 \mathrm{~Gy}$, according to a comparative study showing a higher recurrence rate for patients treated with total doses less than 12Gy [51,59].

\section{Laser Therapy}

\section{Ablative lasers}

Carbon dioxide $(\mathbf{1 0}, \mathbf{6 0 0} \mathrm{nm})$ : Ablation of keloids by carbon dioxide laser $(10,600 \mathrm{~nm})$ can cut and cauterize the lesion, creating a dry surgical environment with relatively minimal tissue trauma. When used as a single modality, the carbon dioxide laser was associated with recurrence rates of $39-92 \%$, and when the carbon dioxide laser was combined with postoperative injected steroids, it was associated with recurrence rates of $25-74 \%$ [53].

Erbium: Yttrium aluminum garnet laser (Er: YAG) (1064 nm): Er: YAG laser showed a decrease of 51.3\% in redness, 50\% in elevation, and $48.9 \%$ in hardness of keloids in one study after treating 21 keloids. The recurrence rate was not reported [53].

Argon 488-nm laser: Similar to the carbon dioxide laser, the argon 488-nm laser can induce collagen shrinkage via generation of excessive localized heat. The argon laser has demonstrated recurrence rates of $45-93 \%$ [53].

\section{Nonablative lasers}

Pulsed-dye laser (585 nm): The 585-nm PDL provides photothermolysis, resulting in microvascular thrombosis. Beginning in the 1980s, authors noted that scars became less erythematous, more pliable, and less hypertrophic after treatment with the 585-nm PDL. The findings were later confirmed using objective measurements of erythema by reflectance spectrometry readings, scar height, and pliability measurements. Because of its efficacy, safety, and relatively low cost, the PDL remains the laser treatment of choice for keloids hypertrophic scars. The concomitant use of TAC reduced symptom scores by $70 \%$ compared with PDL alone (50\%). Side effects are erythema and hypopigmentation [53].

\section{Intralesional \topical apply of following drugs \\ IFN injections}

IFN therapy (Specifically, IFN- $\alpha 2$ b) decreases the synthesis of collagen types I and III, and has antiproliferative properties. IFN$\alpha 2 \mathrm{~b}$ administered intralesionally $(1.5 \times 106 \mathrm{IU}$, given twice daily over 4 days) was found to result in a $50 \%$ reduction of keloid size by 9 days and thus was much more effective than intralesionally injected corticosteroid. Unfortunately, adverse effects are common with IFN treatment, which include flu like symptoms and pain on injection. Although IFN is an expensive form of therapy, it remains a promising therapeutic approach in the management of excessive scars [5]. IFN injected into the suture line of keloid excision sites may be prophylactic for reducing recurrences [50].

\section{5-Fluorouracil}

5-FU, a pyrimidine analogue with antimetabolite activity, inhibits fibroblastic proliferation in tissue culture and is believed to reduce postoperative scarring by decreasing fibroblast proliferation. A previous study found that $85 \%$ of keloids showed more than $50 \%$ improvement after treated once weekly with intralesional 5 -FU $(50 \mathrm{mg} / \mathrm{mL})$ for an average of 7 treatments, with a recurrence rate of $47 \%$ within 1 year of the treatment. The most effective regimen was found to be $0.1 \mathrm{~mL}$ of TAC $(10 \mathrm{mg} /$ $\mathrm{mL}$ ) and $0.9 \mathrm{~mL}$ of $5-\mathrm{FU}(50 \mathrm{mg} / \mathrm{mL})$ up to 3 times a week [50].

\section{Doxorubicin (Adriamycin)}

Doxorubicin is a commonly used chemotherapeutic agent that irreversibly inactivates prolyl 4-hydroxylase in human skin fibroblasts and has been shown to inhibit collagen alpha-chain assembly. Another mechanism of doxorubicin-induced inhibition of collagen synthesis includes the inhibition of the enzyme prolidase, which is key in the process of collagen resynthesis [53].

\section{Bleomycin}

Bleomycin injections cause necrosis of keratinocytes with a mixed inflammatory infiltrate. Several studies have demonstrated that bleomycin can be used effectively to treat keloids and hypertrophic scars. Bleomycin was given at a concentration of $1.5 \mathrm{IU} / \mathrm{mL}$ to 13 patients using the multiple-puncture method. Bleomycin was dripped onto the lesion, and then multiple punctures were made on the lesions using a syringe. Seven 
patients had complete flattening, 5 patients had highly significant flattening, and 1 patient had significant flattening. Fifty patients with keloids were treated with intralesional bleomycin. Three applications were given at 15-day intervals, and a fourth and final application was given 2 months after the third application. Complete flattening was observed in $44 \%$, significant flattening in $22 \%$, adequate flattening in $14 \%$, and no flattening in $20 \%$. Pruritus was relieved completely in $89 \%$ of patients. The combination of bleomycin and intralesional steroids such as triamcinolone has repeatedly shown good results [53].

\section{Verapamil}

Verapamil is a calcium channel blocker that blocks the synthesis and secretion of extracellular matrix molecules (collagen, GAGs, fibronectin) and increases fibrinase. A previous study reported complete resolution of 4 of 6 keloids at 1-year follow-up after surgical removal of the scar and further intralesional injection of verapamil at doses of $2.5 \mathrm{mg} / \mathrm{mL}$ [53]

\section{Retinoic acid}

Retinoic acid decreases normal tonofilament and keratohyalin synthesis, increases the production of mucoid substances and the epidermal cell growth rate, and inhibits DNA synthesis in vitro. In a clinical trial involving 21 patients with 28 keloids and hypertrophic scars, topical retinoic acid was applied for at least 3 months twice daily and showed favorable results in $77-79 \%$ of the lesions. This includes a decrease in the size and symptoms of the scar [53].

\section{Imiquimod $5 \%$ cream}

Imiquimod, an immunomodulator, increases the production of numerous cytokines; IFN-alpha, IFN-gamma, IL-1, IL-4, IL5, IL-6, IL-8, and IL-12 and alters the expression of markers for apoptosis. In one study, 13 keloids were treated with excision in combination with nightly applications of imiquimod 5\% cream for 8 weeks. Ten patients with 11 keloids completed the 6-month study, and no keloids recurred after 6 months. Mild irritation was experienced with the application of imiquimod, and some patients needed a vacation period from the medication [53].

\section{Tamoxifen}

Tamoxifen, a synthetic nonsteroidal antiestrogen used to treat breast cancer, has been shown to inhibit proliferation of keloid fibroblasts and their collagen synthesis in monolayer cultures. A previous study demonstrated that tamoxifen exhibits dermal fibroblast in vitro. Tamoxifen has also been shown to reduce TGFalpha production by keloid fibroblasts in vitro. Mikulec et al have shown that keloid fibroblasts have significantly lower TGF-alpha production when exposed to $16 \mu \mathrm{mol} / \mathrm{L}$ of tamoxifen at day 2 of culture when compared with control keloid fibroblasts [53].

\section{Tacrolimus}

Tacrolimus is an immunomodulator that inhibits TNF-alpha Gli - 1 , an oncogene, has been found to be overexpressed in fibroblasts of keloids. Inhibition of this oncogene may restore the natural apoptosis process and decrease proliferation of the ECM protein. In a previous study, 11 patients used tacrolimus $0.1 \%$ ointment twice daily for 12 weeks on their keloids. Although the results were not statistically significant, the study showed a decrease in induration, tenderness, erythema, and pruritus for most patients [53].

\section{Botulinum Toxin A}

Botulinum Toxin A (BTA) is a neurotoxin that causes a flaccid paralysis of the local musculature and reduces skin tension. This reduction in the skin tensile force during the course of wound healing may represent a novel therapeutic target for treating keloids [53].

\section{Other promising therapies}

The antiangiogenic factors, including the Vascular Endothelial Growth Factor (VEGF) inhibitors (e.g. Bevacizumab). Phototherapy (photodynamic therapy - PDT), UVA-1 therapy, narrow band UVB therapy. Tumor necrosis factor (TNF) alpha inhibitor (etanercept). Recombinant human interleukin (rhIL10) which are directed at decreasing collagen synthesis [51].

Note: a previous study found that $8 \%$ of keloids resolved spontaneously after 5 years [60].

\section{Infiltrated Non-cross-linked Hyaluronic Acid and Cortisone Therapy}

It is a new technique for treating ear keloid. This study had done by Arianna Di Stadio 2016. He used therapeutic injections of cortisone and non-cross-linked hyaluronic acid injections. Cortisone is able to reduce the proliferation of fibroblasts, while hyaluronic acid is able to reduce inflammation by acting on prostaglandin 2 secretions. Cortisone infiltrations were carried out with the following therapeutic scheme: T0, T15, T30, T60. Period between one cortisone infiltration and the other, an infiltration with $0.8 \mathrm{ml}$ Restylan Vital to T7, T21, and T45 was made in inter- and peri-keloid areas (Table 2).

\begin{tabular}{|c|c|c|c|c|c|c|c|}
\hline \multicolumn{7}{|c|}{ Table 2: Infiltration dose at different times during first treatment } \\
\hline & T0 & T7 & T15 & T21 & T30 & T45 & T60 \\
\hline Cortisone & $40 \mathrm{mg}$ & & $40 \mathrm{mg}$ & & $30 \mathrm{mg}$ & & $30 \mathrm{mg}$ \\
\hline HA & & $0.8 \mathrm{ml}$ & & $0.8 \mathrm{ml}$ & & $0.8 \mathrm{ml}$ & \\
\hline
\end{tabular}

Thirty-five days after the end of treatment, the keloid acquired a soft

consistency, was reduced by $40 \%$ and the skin synechia became smaller.

He repeated the previous treatment with the following order (table 3).

Synechia disappeared and the keloid was reabsorbed at 15 days after the last cortisone infiltration. The patient did not show any recurrence of the lesion at the 6- month and 12- month follow-up visits [61]. 
Table 3: Infiltration dose at different times during first treatment

\begin{tabular}{|c|c|c|c|c|c|}
\hline & T0 & T15 & T20 & T45 & T50 \\
\hline Cortisone & $40 \mathrm{mg}$ & & $30 \mathrm{mg}$ & & $20 \mathrm{mg}$ \\
\hline HA & & $0.8 \mathrm{ml}$ & & $0.8 \mathrm{ml}$ & \\
\hline
\end{tabular}

\section{Prevention}

Keloids may arise from any kind of damage in the papillary dermis, even with small injuries like ear piecing and tattoo (Figure 21,22) or inflammatory processes like acne (Figure 23). Therefore, Prevention is the first rule in keloid therapy, so we must take special care in treating patients with a history of keloids (special recommendations for patients and doctors) [8, 53].

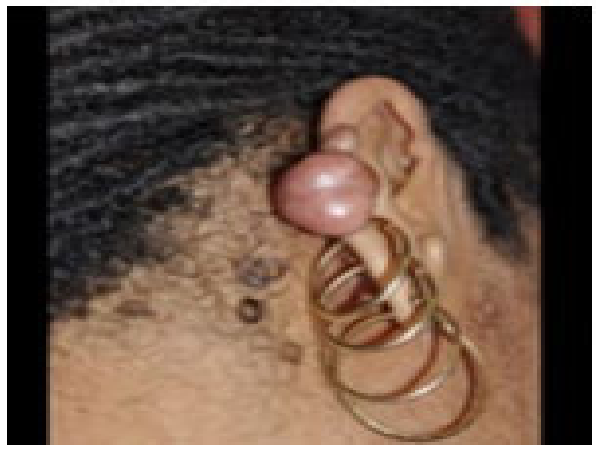

Figure 21: Keloid after ear piecing

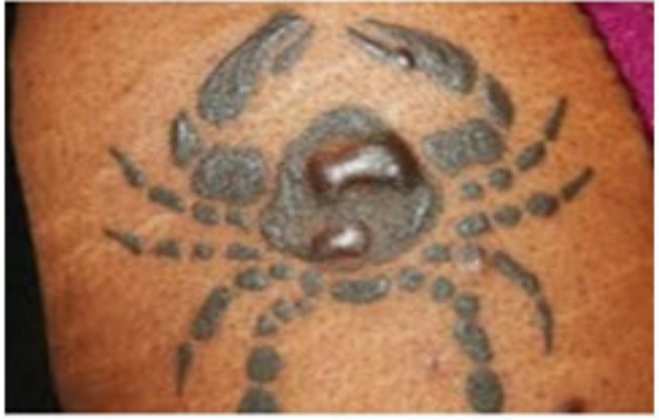

Figure 22: keloid after tattoo

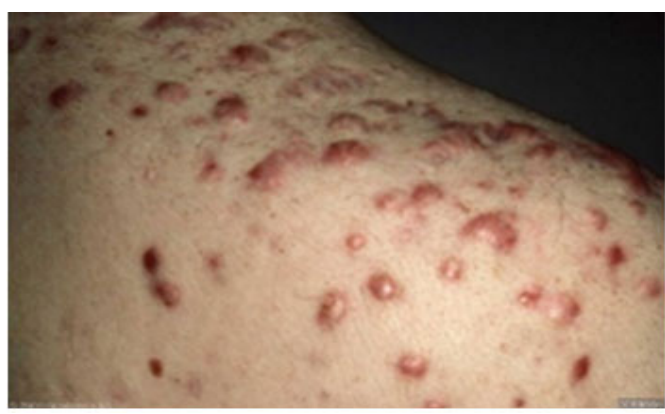

Figure 23: keloid after acne

\section{Recommendations for patients with a history of keloids}

1-Avoid performing nonessential cosmetic surgery in patients known to form keloids; however, the risk is lower among patients who have only earlobe lesions.

2-Avoid skin insults like tattoo and piercing.

3-Proper and effective treatment for acne and other inflammatory lesions.

\section{If surgery is necessary, the patients should}

1-Avoid excessive movements which might cause a widening of the wound.

\section{2-Wear appropriate clothing.}

3-Avoid direct friction on the wound, use silicone gel sheets and micropore over it.

4-For patients with wounds on the earlobes, choose adequate pillows and covers to avoid rubbing the wound while lying.

5-Female patients with wounds on the anterior chest should wear surgical bra and appropriate clothing to prevent increase in tensile strength by the weight of the breasts (Figure 24).

6-Patients with suprapubic scars should use post-operative braces and foam compression.

7-After surgery or injury, apply aseptic precautions and always keep the wound clean.

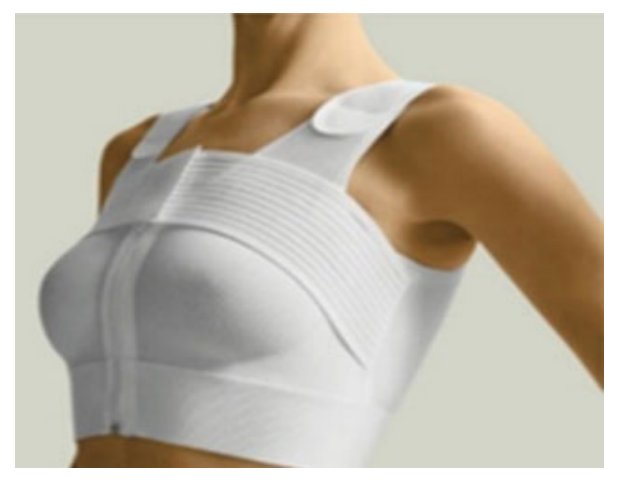

Figure 24: Surgical bra

\section{Recommendations for surgeons}

1-Take proper precautions in surgical patients of black and Western races.

2-Guide skin incisions following skin tension forces.

3-Manipulate the skin atraumatically with delicate instruments, fine suture threads and small diameter needles.

4-Avoid or reduce the use of electrocautery.

5-Suture edges making them well coapted with the least possible tension. 
6-Clean the wound thoroughly, removing foreign bodies, performing adequate debridement, etc.

7-Take all available measures to prevent surgical infection.

8-Indicate compression treatment in high-risk scars.

9-Indicate intralesional corticosteroids or use betatherapy in selected patients.

10-Control and periodic follow up of the evolution of the scar and the patient.

Some pictures of keloids, which located in different sites and caused by different forms of skin injury [27]: (Figure $25,26,27,28,29,30,31,32$ ).

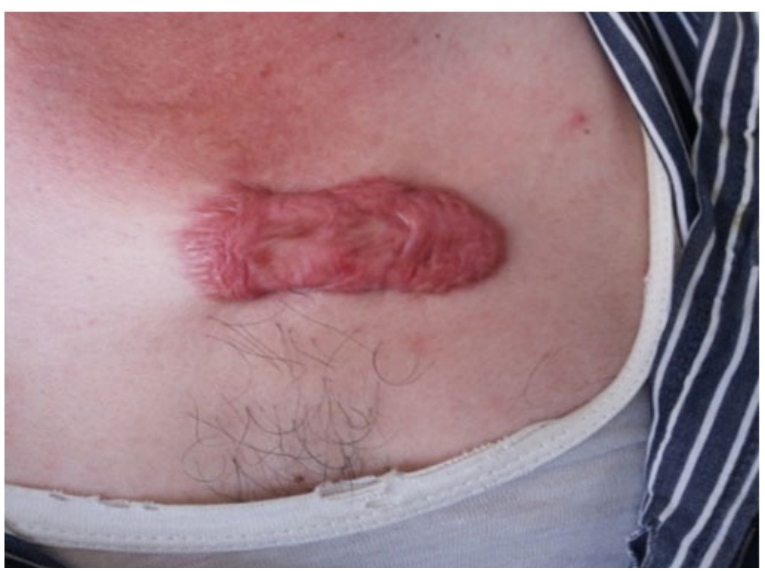

Figure 25: Presternum, spontaneous, male

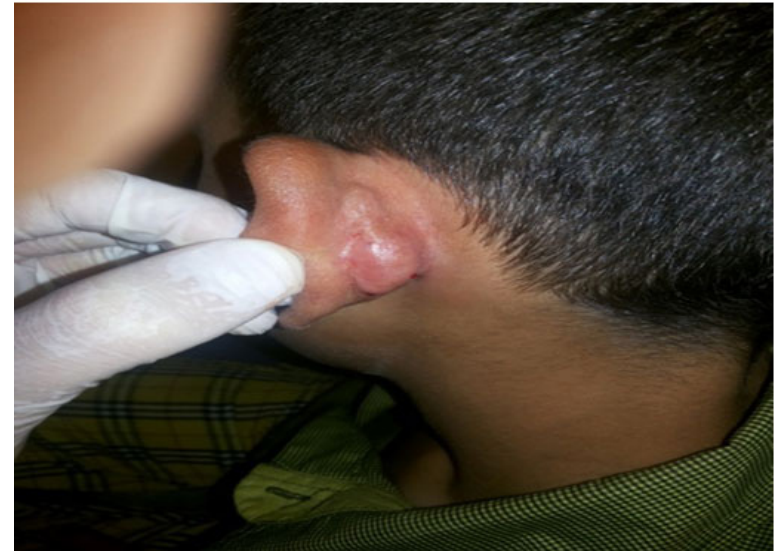

Figure 26: Pinna, surgery, male

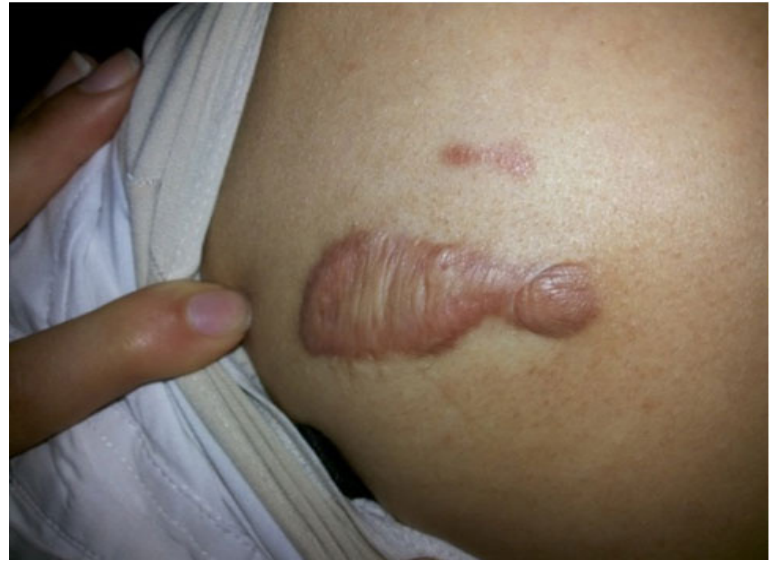

Figure 27: shoulder, surgery, female

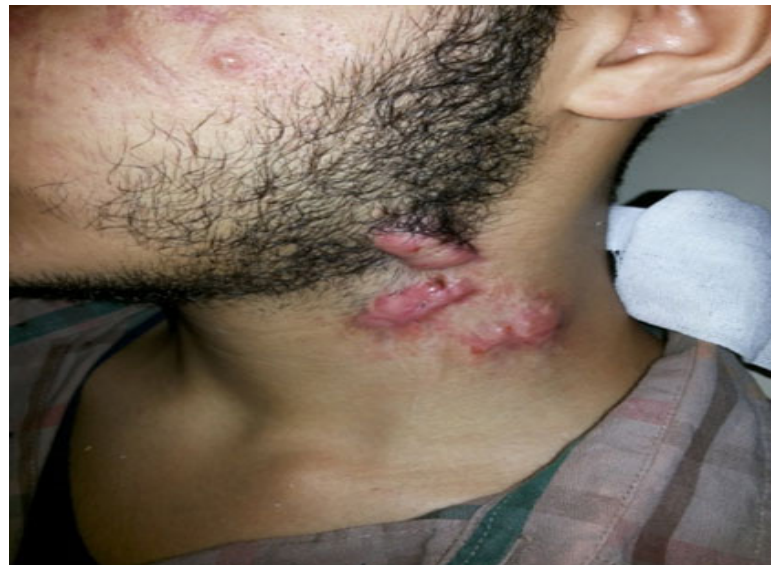

Figure 28: Neck, accident, male

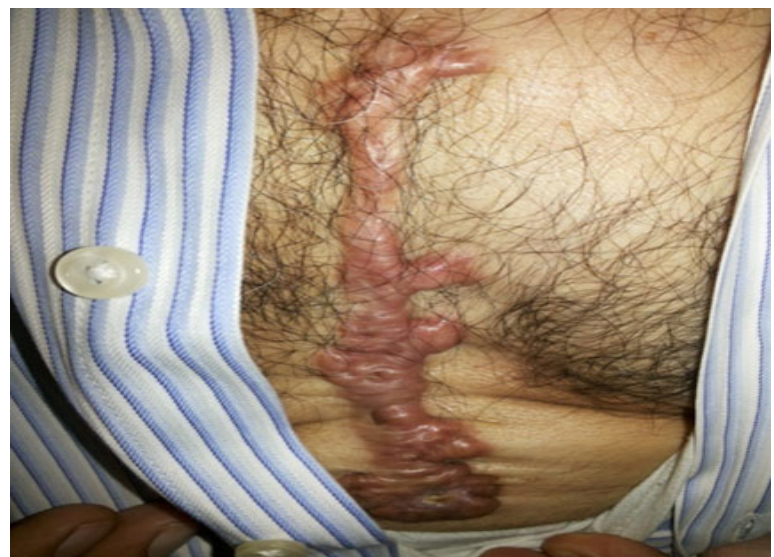

Figure 29: Presternum, surgery, male 


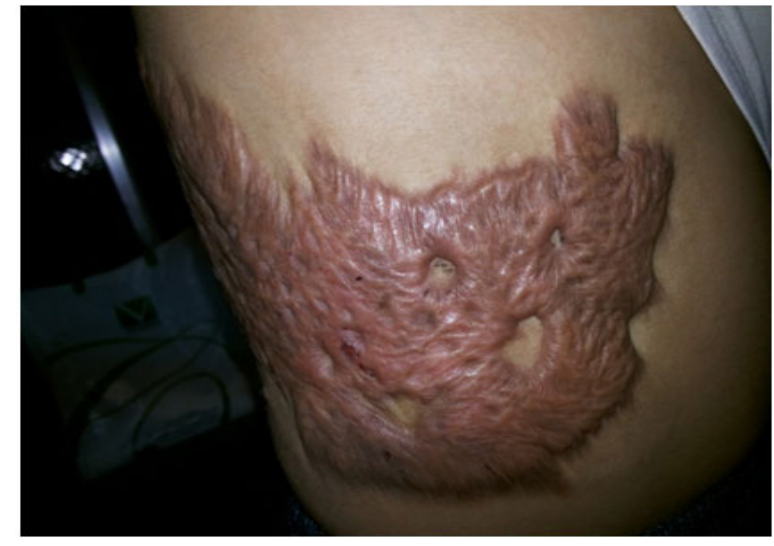

Figure 30: Back, burn, female

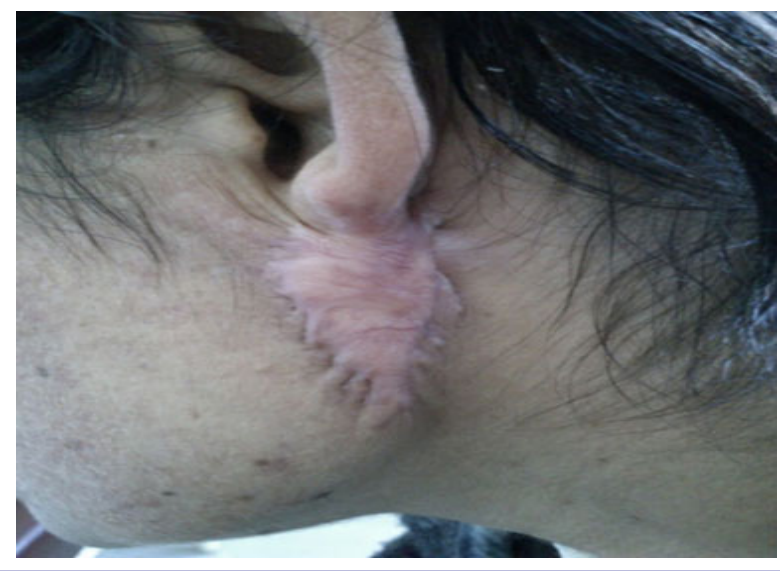

Figure 31: Earlobe, era piercing, female

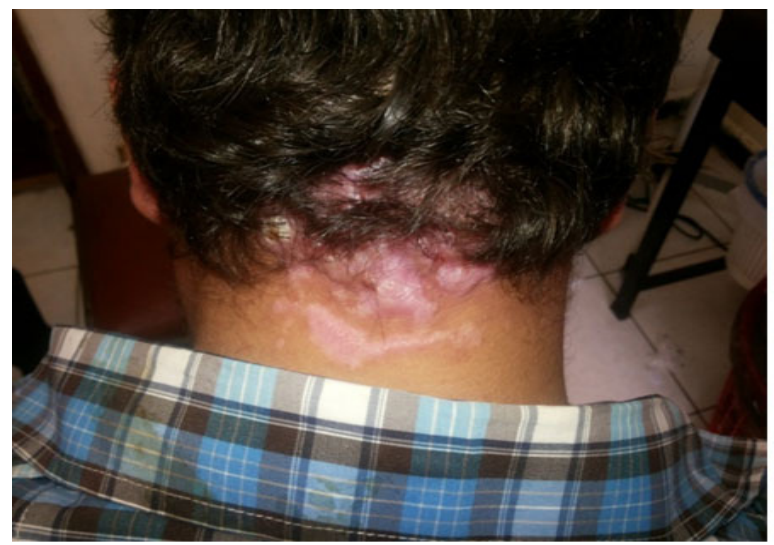

Figure 32: Scalp, acne keloidalis nuchae, male

\section{References}

1. Burrows NP, Lovell CR. Rook textbook of dermatology. 8th edition. Volume 3. Chapter 45.54. keloids and hypertrophic scars.

2. Burton CS, Vaishali E. Bolognia text book. Second edition. Volume 2. Section 15. Chapter 98. Dermal Hypertrophies.

3. Naylor MC, Brissett AE. Current concepts in the etiology and treatment of keloids. Facial Plast Surg. 2012;28(5):504-512. doi: 10.1055/s-0032-1325644

4. Clark JA, Turner ML, Howard L, Stanescu H, Kleta R, Kopp JB. Description of familial keloids in five pedigrees: Evidence for autosomal dominant inheritance and phenotypic heterogeneity. BMC Dermatol. 2009;9:8. doi: 10.1186/1471-5945-9-8

5. Gauglitz GG, Korting HC, Pavicic T, Ruzicka T, Jeschke MG. Hypertrophic Scarring and Keloids: Pathomechanisms and Current and Emerging Treatment Strategies. Mol Med. 2011;17(1-2):113125. doi: $10.2119 /$ molmed.2009.00153

6. Shih B, Garside E, McGrouther DA, Bayat A. Molecular dissection of abnormal wound healing processes resulting in keloid disease. Wound Repair Regen. 2010;18(2):139-153. doi: 10.1111/j.1524475X.2009.00553.x

7. Michael 0. The Search for the Genetic Basis of African Keloids. Annals of Ibadan Postgraduate Medicine. 2012;10(2):53-55.

8. Henriquez CB, Costa F. Resident's Thesis Systematization of treatment of keloid at the Plastic Surgery Unit of the 38th Infirmary of Santa Casa de Misericórdia do Rio de Janeiro. 2003.

9. Muthusubramaniam L, Zaitseva T, Paukshto M, Martin G, Desai T. Effect of collagen nanotopography on keloid fibroblast proliferation and matrix synthesis: implications for dermal wound healing. Tissue Eng Part A. 2014;20(19-20):2728-2736. doi: 10.1089/ten. TEA.2013.0539

10. Zulato E, Favaretto F, Veronese C, Campanaro S, Marshall JD, Romano $S$, et al. ALMS1-deficient fibroblasts over-express extra-cellular matrix components, display cell cycle delay and are resistant to apoptosis. PLoS One. 2011;6(4):e19081. doi: 10.1371/journal. pone.0019081

11. He S, Liu X, Yang Y, Huang W, Xu S, Yang S, et al. Mechanisms of transforming growth factor $\beta 1 /$ Smad signalling mediated by mitogen-activated protein kinase pathways in keloid fibroblasts. Br J Dermatol. 2010;162(3):538-546. doi: 10.1111/j.13652133.2009.09511.x

12. Li J, Cao J, Li M, Yu Y, Yang Y, Xiao X, et al. Collagen triple helix repeat containing-1 inhibits transforming growth factor- $\beta 1$ induced collagen type I expression in keloid. Br J Dermatol. 2011;164(5):1030-1036.

13. Robles DT, Moore E, Draznin M, Berg D. Keloids: Pathophysiology and management. Dermatol Online J. 2007;13(3):9.

14. Shang QX, Yuan R, Wang W. Expression of platelet derived growth factor receptor-beta in fibroblasts of keloid. Zhongguo Xiu Fu Chong Jian Wai Ke Za Zhi. 2000;14(5):278-282. 
15. Hu ZC, Tang B, Guo D, Zhang J, Liang YY, Ma D, et al. Expression of insulin-like growth factor-1 receptor in keloid and hypertrophic scar. Clin Exp Dermatol. 2014;39(7):822-828. doi: 10.1111/ced.12407

16. De Felice B, Ciarmiello LF, Mondola P, Damiano S, Seru R, Argenziano C, et al. Differential p63 and p53 expression in human keloid fibroblasts and hypertrophic scar fibroblasts. DNA Cell Biol. 2007;26(8):541-547.

17. Lu F, Gao J, Ogawa R, Hyakusoku H. Variations in gap junctional intercellular communication and connexin expression in fibroblasts derived from keloid and hypertrophic scars. Plast Reconstr Surg. 2007;119(3):844-851.

18. Vinken M. Role of Connexin-related Signalling in Hepatic Homeostasis and its Relevance for Liver-based in vitro Modelling. World J Gastrointest Pathophysiol. 2011;2(5):82-87. doi: 10.4291/ wjgp.v2.i5.82

19. Sidgwick GP, Bayat A. Extracellular matrix molecules implicated in hypertrophic and keloid scarring. J Eur Acad Dermatol Venereol. 2012;26(2):141-152. doi: 10.1111/j.1468-3083.2011.04200.x

20. Hahn JM, Glaser K, McFarland KL, Aronow BJ, Boyce ST, Supp DM. Keloid-derived keratinocytes exhibit an abnormal gene expression profile consistent with a distinct causal role in keloid pathology. Wound Repair Regen. 2013;21(4):530-544. doi: 10.1111/ wrr.12060

21. Ravn V, Dabelsteen E. Tissue distribution of histo-blood group antigens. APMIS. 2000;108(1):1-28.

22. Wulff BC, Parent AE, Meleski MA, DiPietro LA, Schrementi ME, Wilgus TA. Mast cells contribute to scar formation during fetal wound healing. J Invest Dermatol. 2010;132(2):458-465. doi 10.1038/jid.2011.324

23. Hunasgi S, Koneru A, Vanishree M, Shamala R. Keloid: A case report and review of pathophysiology and differences between keloid and hypertrophic scars. J Oral Maxillofac Pathol. 2013;17(1):116-120. doi: 10.4103/0973-029X.110701

24. XIONG Li-xia, LI Wen-lin, CAI Zhen-yu, ZHOU Ying, XIONG Junping, ZHAO Lin, et al. Suppressive effect of interferon $\gamma$ on IL-13induced fibrosis in fibroblasts. Chinese Journal of Pathophysiology. 2013;3(2013):022.

25. Halim A, Emami A, Salahshourifar I, Kannan T. Keloid scarring: understanding the genetic basis, advances, and prospects. Arch Plast Surg. 2012;39(3):184-189. doi: 10.5999/aps.2012.39.3.184

26. Shaheen A, Khaddam J, Kesh F. Risk factors of keloids in Syrians. BMC Dermatol. 2016;16(1):13. doi: 10.1186/s12895-016-0050-5

27. Bayat A, Arscott G, Ollier WE, McGrouther DA, Ferguson MW. Keloid disease: clinical relevance of single versus multiple site scare. Br J Plast Surg. 2005;58(1):28-37.

28. Olaitan P.B, Olabanji J.K, Oladele A.O, Oseni G.A. Symptomatology of keloids in Africans. Sierra Leone Journal of Biomedical Research. 2013;5(1):29-33.

29. Ramakrishnan KM, Thomas KP, Sundararajan CR. Study of 1,000 patients with keloids in south India. Plast Reconstr Surg. 1974;53(3):276-280
30. Sun LM, Wang KH, Lee YC. Keloid incidence in Asian people and its comorbidity with other fibrosis-related diseases: a nationwide population-based study. Arch Dermatol Res. 2014;306(9):803-808. doi: 10.1007/s00403-014-1491-5

31. Shih B, Bayat A. Genetics of keloid scarring. Arch Dermatol Res. 2010;302(5):319-339. doi: 10.1007/s00403-009-1014-y

32. Nakashima M, Chung S, Takahashi A, Kamatani N, Kawaguchi T, Tsunoda $\mathrm{T}$, et al. A genome-wide association study identifies four susceptibility loci for keloid in the Japanese population. Nat Genet. 2010;42(9):768-771. doi: 10.1038/ng.645

33. Marneros AG, Norris JE, Watanabe S, Reichenberger E, Olsen BR. Genome scans provide evidence for keloid susceptibility loci on chromosomes 2q23 and 7p11. J Invest Dermatol. 2004;122(5):11261132.

34. Brown JJ, Ollier WE, Thomson W, Bayat A. Positive association of HLA-DRB1*15 with keloid disease in Caucasians. Int J Immunogenet. 2008;35(4-5):303-307. doi: 10.1111/j.1744-313X.2008.00780.x

35. Mandal A, Imran D, Rao GS. Spontaneous keloids in siblings. Ir Med J. 2004;97(8):250-251.

36. Park TH, Park JH, Tirgan MH, Halim AS, Chang $\mathrm{CH}$. Clinical Implications of Single Versus Multiple-Site Keloid Disorder: A Retrospective Study in an Asian population. Ann Plast Surg. 2015;74(2):248-251. doi: 10.1097/SAP.0b013e3182a2b537

37. Gao FL, Jin R, Zhang L, Zhang YG. The contribution of melanocytes to pathological scar formation during wound healing. Int J Clin Exp Med. 2013;6(7):609-613.

38. Goyal S, Saini I, Goyal S. Familial Keloid in Indian Scenario: Case Report and Review of Literature. OALibJ. 2015;2(7):1-4.

39. Wolfram D, Tzankov A, Pülzl P, Piza-Katzer H. Hypertrophic scars and keloids -a review of their pathophysiology, risk factors, and therapeutic management. Dermatol Surg. 2009;35(2):171-181. doi: 10.1111/j.1524-4725.2008.34406.x

40. Perdanakusuma DS. The effect of melanin concentration on collagen accumulation in keloid. Folia Medica Indonesiana. 2006;42(4):218227.

41. Ogawa R, Okai K, Tokumura F, Mori K, Ohmori Y, Huang C, et al. The relationship between skin stretching/contraction and pathologic scarring: The important role of mechanical forces in keloid generation. Wound Repair Regen. 2012;20(2):149-157. doi: 10.1111/j.1524-475X.2012.00766.x

42. Mouhari-Toure A, Saka B, Kombaté K, Akakpo S, Egbohou P, Tchangaï-Walla $\mathrm{K}$, et al. Is There an Association between Keloids and Blood Groups? ISRN Dermatol. 2012;2012:750908. doi: 10.5402/2012/750908

43. Kelly AP. Update on the Management of Keloids. Semin Cutan Med Surg. 2009;28(2):71-76. doi: 10.1016/j.sder.2009.04.002

44. Ogawa R, Mitsuhashi K, Hyakusoku H, Miyashita T. Postoperative Electron-Beam Irradiation Therapy for Keloids and Hypertrophic Scars: Retrospective Study of 147 Cases Followed for More Than 18 Months. Plast Reconstr Surg. 2003;111(2):547-553. 
45. Jannati P, Aref S, Jannati A A, Jannati F, Moravvej H. Comparison of Therapeutic Response of Keloids to Cryotherapy Plus Intralesional Triamcinolone Acetonide or Verapamil Hydrochloride. Journal of Skin and Stem Cell. 2015;2(1):e29284.

46. Monarca C, Maruccia M, Palumbo F, Parisi P, Scuderi N. A rare case of Postauricular Spontaneous Keloid in an Elderly Patient. In Vivo. 2012;26(1):173-175.

47. Sharquie KE, Al-Dhalimi MA. Keloid in Iraqi Patients. A Clinicohistopathologic Study. Dermatol Surg. 2003;29(8):847-851.

48. Oittinen HA, O'Shaughnessy M. Multiple nonsyndromic spontaneous keloids in allergic disease. Plast Reconstr Surg. 2007;119(2):762763.

49. Philandrianos C, Kerfant N, Jaloux C Jr, Martinet L, Bertrand B, Casanova D. Keloid scars (part I): Clinical presentation, epidemiology, histology and pathogenesis. Ann Chir Plast Esthet. 2016;61(2):128135. doi: 10.1016/j.anplas.2015.09.005

50. Weledji EP, Ngwane S. The Management of Keloids and Hypertrophic Scars. Darlington and County Durham Medical Journal. 2012;6(2):3945.

51. Ogawa R. Keloid and Hypertrophic Scars Are the Result of Chronic Inflammation in the Reticular Dermis. Int J Mol Sci. 2017;18(3). pii: E606. doi: 10.3390/ijms18030606

52. Berman B, Elston DM. Keloid and Hypertrophic Scar Clinical Presentation. Medscape. 2016.
53. Ogawa R, Akaishi S, Hyakusoku H. Differential and Exclusive Diagnosis of Diseases That Resemble Keloids and Hypertrophic Scars. Ann Plast Surg. 2009;62(6):660-664. doi: 10.1097/ SAP.0b013e31817e9d67

54. Moshref SS, Mufti ST. Keloid and Hypertrophic Scars: Comparative Histopathological and Immunohistochemical Study. JKAU: Med Sci. 2010;17(3):3-22. doi: 10.4197/Med. 17-3.1

55. Juckett G, Adams HH. Management of Keloids and Hypertrophic Scars. Am Fam Physician. 2009;80(3):253-260.

56. O'Brien L, Jones DJ. Silicone gel sheeting for preventing and treating hypertrophic and keloid scars. Cochrane Database Syst Rev. 2013;(9):CD003826. doi: 10.1002/14651858.CD003826.pub3

57. Viera MH, Amini S, Valins W, Berman B. Innovative therapies in the treatment of keloids and hypertrophic scars. J Clin Aesthet Dermatol. 2010;3(5):20-26.

58. Shejbal D, Bedekoviæ V, Ivkiæ M, Kalogjera L, Aleriæ Z, Drvis P. Strategies in the Treatment of Keloid and Hypertrophic Scars. Acta clin Croat. 2004;43:417-422.

59. Smith OJ, McGrouther DA. The natural history and spontaneous resolution of keloid scars. JPlast Reconstr Aesthet Surg. 2014;67(1):8792. doi: 10.1016/j.bjps.2013.10.014

60. ARIANNA DI STADIO. Ear Keloid Treated with Infiltrated Noncross-linked Hyaluronic Acid and Cortisone Therapy. In vivo. 2016;30(5):695-700. 